\title{
Impact of Tropical Cyclones on the Global Ocean: Results from Multidecadal Global Ocean Simulations Isolating Tropical Cyclone Forcing $\mathscr{O}$
}

\author{
HUI LI \\ Department of Atmospheric Sciences, University of Illinois at Urbana-Champaign, Urbana, Illinois, and \\ Department of Geology and Geophysics, Yale University, New Haven, Connecticut \\ RYAN L. SRIVER \\ Department of Atmospheric Sciences, University of Illinois at Urbana-Champaign, Urbana, Illinois
}

(Manuscript received 13 April 2018, in final form 20 August 2018)

\begin{abstract}
Tropical cyclone (TC)-induced ocean vertical mixing can alter the upper-ocean temperature structure, influencing ocean heat content variability and meridional ocean heat transport. TC-ocean interactions can influence tropical variability on seasonal to interannual time scales. Here the impacts of TCs on the global ocean and the associated feedbacks are investigated using a hierarchy of high-resolution global ocean model simulations featuring the Community Earth System Model (CESM). The aim is to understand the potential impact of the model's self-generated transient TC events on the modeled global ocean. Two ocean-only simulations are performed using the atmosphere boundary conditions from a fully coupled preindustrial CESM simulation configured with $0.25^{\circ}$ atmosphere resolution and the nominal $1^{\circ}$ ocean resolution (with $\sim 0.25^{\circ}$ meridional resolution in the tropics). The high-resolution coupled model is capable of directly simulating TC events with wind structure and climatology generally consistent with observations. TC effects at the ocean-atmosphere boundary are filtered out in one of the ocean simulations (OCN_FILT) while fully retained in the other (OCN_TC) in order to isolate the effect of the TCs on regional and global ocean variability across multiple time scales (from intraseasonal to interdecadal). Results show that the modelsimulated TCs can 1) alter surface and subsurface ocean temperature patterns and variability; 2) affect ocean energetics, including increasing ocean mixed layer depth and strengthening subtropical gyre and meridional overturning circulations; and 3) influence ocean meridional heat transport and ocean heat content from seasonal to interannual time scales. Results help provide insights into the model behavior and the physical nature of the effect of TCs within the Earth system.
\end{abstract}

\section{Introduction}

Tropical cyclones (TCs) can cause extreme air-sea interactions and generate vigorous responses in the upper ocean. The upper-ocean response is typically characterized by sea surface cooling and subsurface warming (Price 1981; Ginis 2002; Cheng et al. 2015), which is induced by a combination of physical processes including enthalpy flux exchange, Ekman pumping, geostrophic

Supplemental information related to this paper is available at the Journals Online website: https://doi.org/10.1175/JCLID-18-0221.s1.

Corresponding author: Hui Li, hui.li.h1738@yale.edu advection, and ocean vertical mixing. Vertical mixing is the primary contributor to TC-induced vertical temperature changes and is caused by shear instability at the base of the ocean mixed layer associated with the nearinertial currents generated by TC wind forcing (Cuypers et al. 2013; Jaimes and Shay 2009). After TC passage, the near-surface cooling can be restored by surface heat flux adjustment in about 30-60 days (Dare and McBride 2011), while the subsurface warming can persist beyond the seasonal time scale, resulting in a net heating of the ocean (Emanuel 2001; Sriver and Huber 2007; Mei et al. 2013; Cheng et al. 2015). Studies show that TC-induced ocean mixing may potentially influence global ocean heat content and ocean heat transport ( $\mathrm{Hu}$ and Meehl 2009; Jansen and Ferrari 2009; Vincent et al. 2013; Bueti 
et al. 2014; Jullien et al. 2012), suggesting that TCs, as transient extreme weather events, may actively influence the large-scale climate mean state and variability.

While previous studies have provided important insights into TCs' roles within Earth's climate system, estimates of TC-induced ocean heat uptake and the impact on ocean dynamics are not well understood. Major challenges include the lack of observational data and limitations in using numerical models to simulate the effect of small-scale TCs on the large-scale climate. Research has shown that atmospheric general circulation models (AGCMs) with grid spacing finer than $0.5^{\circ}$ can spontaneously generate TC events within the modeled large-scale climate, with long-term TC climatology comparable to observations (Wehner et al. 2014; Small et al. 2014; Bacmeister et al. 2018; Li and Sriver 2016, 2018). The $0.25^{\circ}$ AGCMs are able to generate very intense category $5 \mathrm{TCs}$, though they underestimate their frequency (Bacmeister et al. 2018; Li and Sriver 2018; Davis 2018). Within the coupled atmosphere-ocean climate framework, the model's self-generated TCs can induce realistic air-sea flux anomalies, ocean temperature responses, and anomalous ocean heat uptake (Li et al. 2016; Li and Sriver 2016). These highresolution climate model configurations provide an innovative and valuable platform for understanding the physical processes influencing TC-climate interactions. Meanwhile, as climate models move toward TCresolving resolutions, it is important to understand the processes and biases related to the potential feedbacks of the model's self-generated TCs on the modeled climate mean state in order to better understand model behavior and constrain uncertainties in climate simulations.

Here we investigate the impact of TCs on the global ocean utilizing a "TC resolving" configuration of the Community Earth System Model (CESM). We perform a suite of decadal-scale ocean-only simulations forced with atmosphere boundary conditions from a high-resolution fully coupled simulation with $0.25^{\circ}$ atmosphere and $1^{\circ}$ ocean resolutions, and we remove the TC signatures from the boundary forcing in one of the model experiments to isolate the effect of TCs on regional to global ocean variability. We aim to better understand how the model's self-generated TCs can influence the model-simulated global ocean in various aspects and across different time scales and provide insights into the effect of resolved transient extreme weather events on the simulated mean climate.

The paper is structured as follows. Section 2 summarizes the numerical methods, which include model description, experiment design, and TC-filtering technique. The main results are described in section 3 , in which we first summarize the model-simulated TC activity and then diagnose the mean state and variability of TC-induced ocean surface and subsurface temperature responses. We then analyze the ocean's dynamic responses to TCs and estimate TC-induced ocean heat anomalies and meridional transport. Main conclusions and caveats will be discussed in section 4 .

\section{Methods}

\section{a. Model description}

We use CESM, version 1.2.2 (CESM 1.2.2; Hurrell et al. 2013). CESM includes atmosphere, land, ocean, and sea ice components that can communicate with one another through a central coupler component model. The model configuration used in this study is the same as described in Li and Sriver (2018), and we provide a brief summary here. The atmosphere component is the Community Atmosphere Model, version 5.3 (CAM5.3; Neale et al. 2013), configured with the spectral element (SE) dynamic core, $0.25^{\circ}$ horizontal grid spacing, and 30 vertical levels. The land component is the Community Land Model, version 4 (CLM4; Lawrence et al. 2012). The ocean component is the Parallel Ocean Program, version 2 (POP2; Smith et al. 2010), and the sea ice component is the Los Alamos Sea Ice Model (CICE). The ocean model uses the nominal $1^{\circ}$ ocean horizontal resolution on the displaced pole grid (Danabasoglu et al. 2006). The ocean model features uniform zonal grid spacing of $1.125^{\circ}$ and varying meridional grid spacing that is finest near the equator $\left(0.27^{\circ}\right)$ and grows coarser $\left(\sim 0.5^{\circ}\right)$ poleward. The ocean model has 62 vertical levels from the surface down to 6000-m depth. The layer thickness increases from $10 \mathrm{~m}$ at the near surface to $250 \mathrm{~m}$ at the deepest level. POP2 uses the $K$-profile parameterization (KPP; Large et al. 1994) as the vertical mixing scheme, which includes processes of shear instability, internal wave breaking, double diffusion, convection, and tidal mixing. In KPP, the boundary layer and the ocean interior are parameterized based on different physics. Zedler et al. (2002) found that the gradient Richardson number instability mixing due to resolved shear in KPP is particularly efficient for simulating interior mixing under TC conditions. The Gent-McWilliams (GM) parameterization (Gent and McWilliams 1990) is used to approximate the effect of mesoscale eddy mixing. The coupler is the CPL7 (Craig et al. 2011). Airsea fluxes are calculated in the coupler on the ocean grid.

Currently, the movement toward high-resolution coupled climate modeling is primarily focused on the atmosphere components, and resolutions have reached scales on which realistic TCs form spontaneously within the models. Thus, these models can be useful tools to 
understand how TC activity varies with, and contributes to, climate variability. The nominal $1^{\circ}$ ocean horizontal resolution is the "workhorse" configuration that is heavily used in the current generation of fully coupled climate simulations, including national and international climate assessments. However, the relatively low resolution is not fine enough to resolve small-scale ocean features that are important for TC-ocean interactions, relying on parameterizations to represent subgrid-scale processes. Li and Sriver (2016) found that TC-induced vertical mixing and the associated vertical heat transport are better captured in the eddy-resolving $0.1^{\circ}$ ocean model than in the $1^{\circ}$ ocean model, though the $1^{\circ}$ model can still generally capture both local effects (e.g., surface cooling and subsurface warming) and basin-scale responses (e.g., ocean heat convergence). The relatively coarse $1^{\circ}$ ocean resolution is a key limitation of the current study and is discussed in more detail in the following sections.

\section{b. Experiment design}

We perform a suite of model simulations including a fully coupled run and two ocean-only runs, with and without TCs. The fully coupled simulation is an extension of the experiment described in Li and Sriver (2018), with over 72 years of simulation length under preindustrial climate conditions. In the current study, we make use of the last 30 years of this simulation (named CPL). We then perform an ocean-only run (named OCN_TC), using the same POP2 ocean model and forced with the same atmosphere bottom boundary conditions from CPL, starting with the same ocean conditions at the beginning of the $30-\mathrm{yr}$ period. The boundary conditions from CPL include all the model's self-generated TC signatures at the air-sea interface, including surface wind, pressure, temperature, precipitation, etc. Therefore, the OCN_TC contains the combined impact of TCs on the ocean. We filter out the TC signatures from the atmosphere bottom boundary in OCN_TC and use the filtered boundary conditions to force an additional ocean-only simulation (named OCN_FILT) without TC impacts. We diagnose TCs' effect on the ocean by comparing the results from 30 years of OCN_TC and OCN_FILT. Hereafter, the term "anomaly" will refer to the difference between ocean model simulation with TC forcing and the ocean model simulation without TC forcing (OCN_TC minus OCN_FILT).

As documented in Li and Sriver (2018), we made several changes in CPL to achieve more realistic TCinduced ocean responses, which include increased ocean coupling frequency from the default daily to every $2 \mathrm{~h}$ and modified the surface drag coefficient (Moon et al.
2007) to accommodate high TC wind speeds. Coupling frequency has been shown to be important for simulating realistic SST feedbacks to TCs by influencing the alignment between TCs and the cold wake (Scoccimarro et al. 2017). Furthermore, a higher coupling frequency may be important for high-resolution climate modeling in general, as it is essential for capturing the highfrequency (subdaily) wind variations in the highresolution models that induce ocean internal inertial wave responses and the associated ocean mixing and heat transport. Modification of the drag coefficient parameterization is also critical to simulating realistic TCocean interactions, as the default drag coefficient used in the coupled CESM (Large and Yeager 2004), though validated for wind speed below $21 \mathrm{~m} \mathrm{~s}^{-1}$, tends to overestimate momentum input into the ocean for high wind regime (Powell et al. 2003; Moon et al. 2007; Bueti et al. 2014; Li and Sriver 2016). Therefore, we adopt the surface drag scheme in Moon et al. (2007) for a more realistic representation of TC-induced wind stress on the ocean. The ocean-only runs (OCN_TC and OCN_FILT) use the ocean-sea ice configuration of CESM, and we keep all the model settings in the ocean-sea ice component and the coupler consistent with CPL.

We keep the resolution of the atmosphere bottom boundary forcing at $\sim 0.25^{\circ}$ to maintain the highresolution wind stress in the ocean-only runs. The raw atmosphere boundary forcing fields are regridded to a latitude-longitude grid in order to be used to force the ocean component. The regridding process may introduce slight inconsistencies with the original forcings in CPL, so the ocean mean state in OCN_TC is not exactly the same as with CPL. This is an inevitable issue and a major challenge for similar kinds of highresolution modeling experiments. Nonetheless, we find that the difference is generally small (see Figs. S1-S3 in the online supplemental material) and that the ocean conditions simulated in OCN_TC and OCN_FILT are reasonable (more discussions in section 4). We regard the first three years of the ocean simulations as the adjustment period, corresponding to the first $10 \%$ of the simulation. This is likely a conservative estimate given the small differences in mean state between simulations (Figs. S5, S6). The long-term mean climatology analyses are therefore based on the last 27 years of the model results.

\section{c. TC filtering}

To remove TCs from the atmosphere boundary, we adopt a similar approach as described in (Wang et al. 2012a,b). We consider all the relevant atmosphere boundary forcing fields at 6-hourly and daily coupling frequency. The 6-hourly variables include wind, surface pressure, surface temperature, and relative humidity. 
Daily variables include shortwave and longwave radiation and precipitation. We first detect and track all the TC events based on the 6-hourly atmosphere output in the fully coupled run, using the tracking method described in Li and Sriver (2018). For each TC event, we loop over the TC days to apply a low-pass Lanczos filter (Duchon 1979) at each TC location with 8-day cutoff frequency to all the relevant fields over the window of [i_day $-1: f_{-}$day +8 ], where $i_{-}$day and $f_{-}$day are the first and last day of the TC event. The filter is applied over a $10^{\circ} \times 10^{\circ}$ domain surrounding the TC center. The cutoff frequency is chosen based on the typical duration of TCs, and it is the same as in Wang et al. (2012b). We also performed an additional sensitivity test of the filter length window ( 5 day, 8 day, 10 day) to ensure that the 8 -day window is a reasonable choice (see Fig. S4). The $10^{\circ} \times 10^{\circ}$ domain size is chosen to cover the TC area based on the simulated TC size by visually inspecting the model-simulated TC wind circulations. For each event, since the filter is applied at each location over the time window of the entire TC lifetime, the overlapping area along the TC track is only counted once. We also apply linear ramping in time (with a 4-day time zone) and space (with a $5^{\circ}$ area on each lateral boundary of the $10^{\circ} \times 10^{\circ}$ domain) for a smooth transition from the filtered field to the original field. The ramping weight is as in Wang et al. (2012b), and here we provide a brief overview. For each $15^{\circ} \times 15^{\circ} \mathrm{TC}$ domain, the spatial ramping is defined as

$\operatorname{ramp}_{\text {space }}$

$=\left\{\begin{array}{l}0, \text { if within the } 10^{\circ} \times 10^{\circ} \text { domain } \\ \left(x-x_{\text {in }}\right) /\left(x_{\text {out }}-x_{\text {in }}\right), \text { if } x \text { within the ramping area. } \\ 1, \text { if } x \text { outside the } 15^{\circ} \times 15^{\circ} \text { area }\end{array}\right.$

Here $x_{\text {in }}$ is the boundary of the filtered $10^{\circ} \times 10^{\circ}$ inner domain, and $x_{\text {out }}$ is the boundary of the $15^{\circ} \times 15^{\circ}$ outer domain. Similarly, for temporal ramping, the inner boundary is the filtered time domain [ $i$ day $-1: f$ day +8$]$, and the outer boundary is 4 days before and after the inner domain. The temporal ramping weight, denoted as ramp $_{\text {time, }}$, is therefore defined as

$$
\begin{aligned}
& \text { ramp }_{\text {time }} \\
& =\left\{\begin{array}{l}
0, \text { if } i \_ \text {day }-1 \leq t \leq f \_ \text {day }+8 \\
{\left[\left(i \_ \text {day }-1\right)-t\right] / 4, \text { if } i \_ \text {day }-5 \leq t<i \_ \text {day }-1} \\
{\left[t-\left(f \_ \text {day }+8\right)\right] / 4, \text { if } f \_ \text {day }+8<t \leq f \_ \text {day }+12} \\
1, \text { if } t<i \_ \text {day }-5 \text { or } t>f \_ \text {day }+8
\end{array}\right.
\end{aligned}
$$

The total ramping weight is

$$
\text { weight }=\left(1-\operatorname{ramp}_{\text {space }}\right) \times\left(1-\text { ramp }_{\text {time }}\right) .
$$

Taking the horizontal wind $U$ as an example, the final value $U_{\text {final }}$ is weighted with the filtered value $U_{\text {filtered }}$ and the original value $U_{\text {original }}$ :

$$
U_{\text {final }}=\text { weight } \times U_{\text {filtered }}+(1-\text { weight }) \times U_{\text {original }} .
$$

More details about the procedure can be found in the supplemental material. Figures 1a and 1b show an example of surface winds and the associated surface temperature under a TC event before and after applying the filter. Composite time series of TC wind speed anomalies for all storms globally with and without filtering are shown in Figs. 1c and 1d. The wind speed series of each TC day is averaged over a TC-centered $4^{\circ} \times 4^{\circ}$ domain, and the anomalies are referenced to the average wind speed of [TC day - 7: TC day - 3]. Results show that the filtering technique can remove the majority of the TC signature from the atmosphere boundary.

\section{Results}

\section{a. Model-simulated TC activity}

Figure 2a compares 30 years of accumulated TC tracks in the observational best track (1985-2014) and in the fully coupled simulation (CPL). The observational best track data are from NOAA's Storm Prediction Center and the U.S. Navy's Joint Typhoon Warning Center. As is discussed in several modeling studies (Small et al. 2014; Scoccimarro et al. 2011), the coupled high-resolution CESM can simulate a global TC number (Table 1) and spatial distribution generally in agreement with observations. The $30-y r$ simulation used in this study has 83 annual storms on average, which is less than the observed average annual number of 95 . The major discrepancy is in the North Atlantic basin, where the coupled model underestimates TC number and intensity (Small et al. 2014; Li and Sriver 2018). Note that the model simulation is under preindustrial climate conditions, while the observational tracks are from the historical period. Some differences may be a result of different climate conditions. The lack of TC activity in the North Atlantic is a common problem among the coupled modeling studies. The biases in this specific CESM coupled model configuration are evaluated in detail in Li and Sriver (2018), in which they found that the lack of Atlantic TCs is mainly due to overestimated vertical wind shear over the hurricane main development region and the cold SST bias upstream.

The model-simulated seasonal cycle of TC frequency is compared with observations in Fig. 3a. The modelsimulated TC seasonality is consistent with observations 

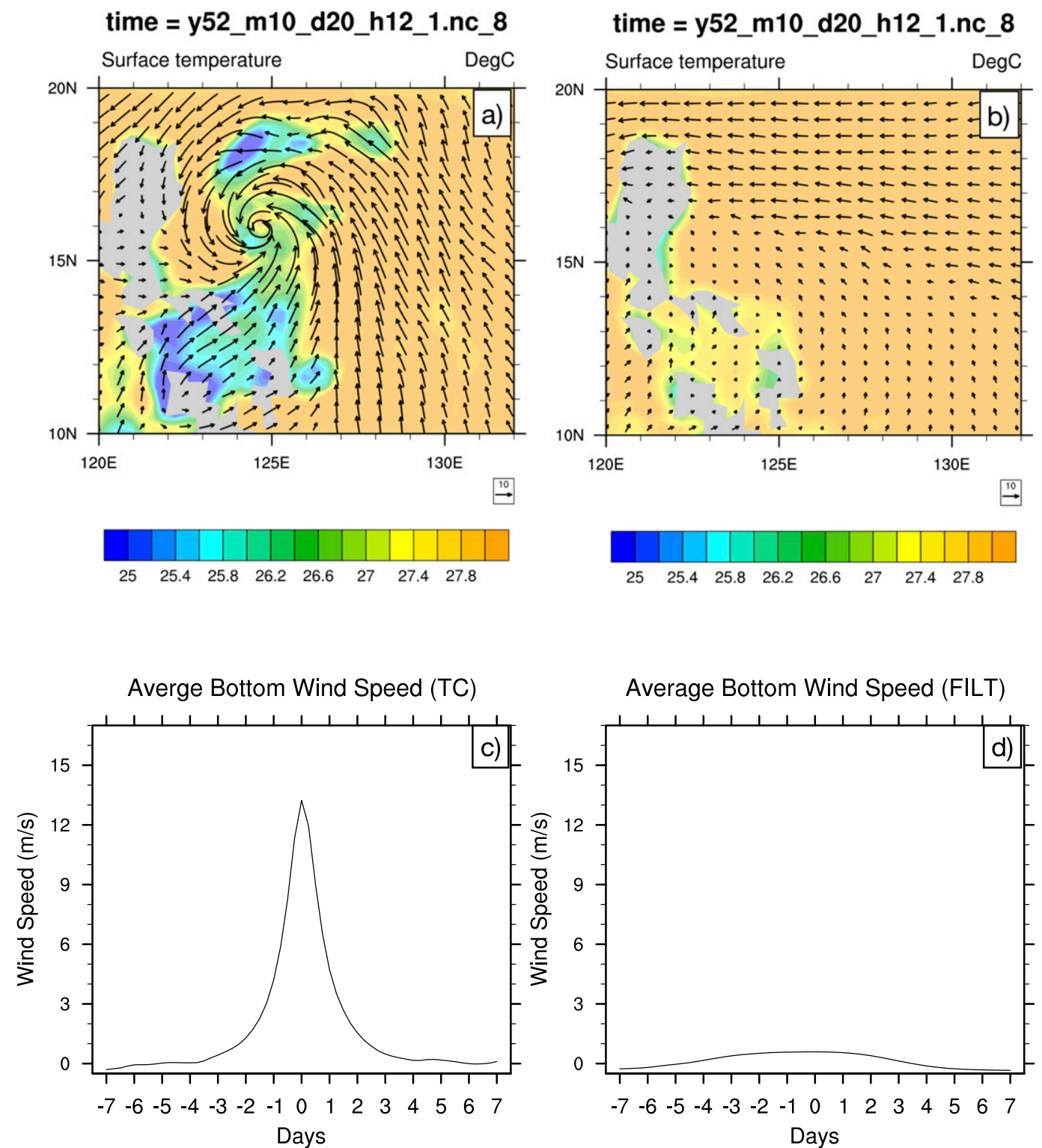

FIG. 1. Examples of TC filtering. Atmosphere bottom surface temperature (colors) and wind (vectors) under a TC event (a) before and (b) after applying the filter; composite time series of average wind speed anomalies over a $4^{\circ} \times 4^{\circ}$ domain surrounding the TC center (c) before and (d) after applying the filter, with 0 on the $x$ axis indicating the time of TC occurrence. The anomalies are referenced to the average wind from day -7 to day -3 in the respective model output.

in most of the basins, including the North Atlantic (AT), eastern Pacific (EP), northwestern Pacific (NWP), and the Southern Hemisphere (SH). However, the model does not capture the "double peak" seasonal cycle in the northern Indian Ocean (IO). Figure 3b shows the frequency distribution of the simulated storm lifetime maximum wind speed. Note that the model and the observations are under different climate conditions, and here we use the observations mainly as a reference. The simulated TC frequency and intensity are largely underestimated in the North Atlantic. The intensity distribution in the northwestern Pacific, Indian Ocean, and the Southern Hemisphere tends to concentrate on the category 2-4 wind regime. The maximum TC wind speed of the most intense events in the model is lower than in the observations, which may be partly due to the different climate conditions between model (preindustrial) and observations (historical) and/or due to the atmosphere model resolution. Davis (2018) shows that the $0.25^{\circ}$ atmosphere resolution is not fine enough 

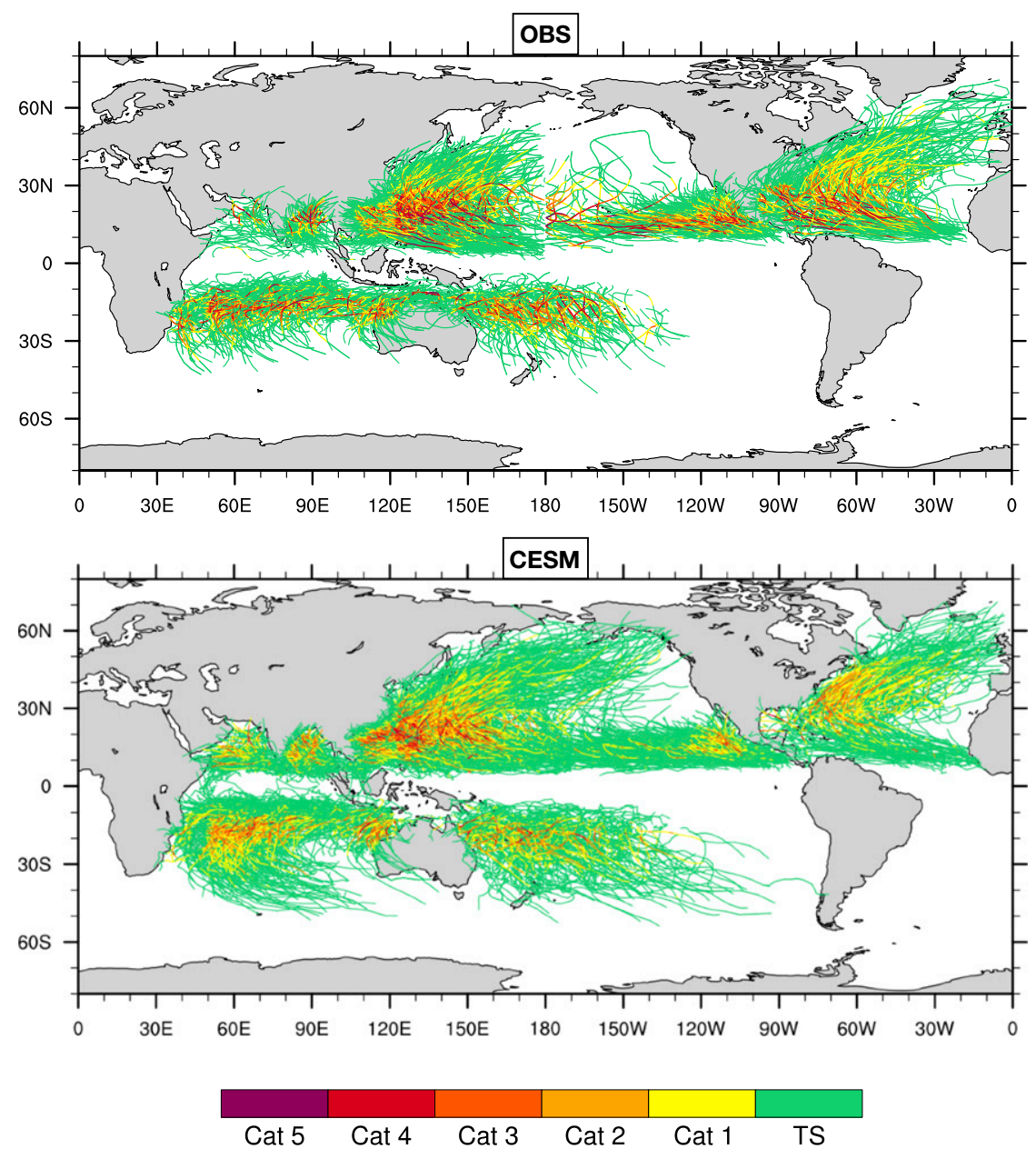

FIG. 2. Accumulated TC tracks over 30 years in the (top) observational best track during 1985-2014 and (bottom) the coupled CESM simulation.

to simulate realistic frequency of category 4 and 5 TCs, though this effect could be partially compensated by the larger TC size and broad outer wind structure.

In addition, the modeled TCs have longer tracks and reach higher latitudes than the observations. This is partly attributed to the TC detection and tracking scheme that includes the extratropical transition phase. Figure $3 \mathrm{c}$ shows the latitudinal distribution of the longterm mean annually accumulated total TC power dissipation index (PDI). PDI is defined (Emanuel 2005) as

$$
\mathrm{PDI}=\int_{0}^{\tau} V_{\max }^{3} d t
$$

where $V_{\max }$ is the maximum surface wind speed at a given time of a storm, and $\tau$ is the lifetime of the TC event. PDI is an indicator of the integrated TC power. The modeled PDI is smaller than the observations at the TC peak latitudes in the Northern Hemisphere, which is likely due to the lack of TC activity in the North Atlantic and underestimated TC intensity in general. The

TABLE 1. Average annual TC number (with 95\% confidence interval) in the observational records during 1985-2014 and coupled CESM simulation.

\begin{tabular}{|c|c|c|c|c|c|c|c|}
\hline & & Global & $\mathrm{AT}$ & EP & $\mathrm{IO}$ & NWP & $\mathrm{SH}$ \\
\hline \multirow[t]{2}{*}{ Obs } & All & $95.4 \pm 8.6$ & $15.2 \pm 4.6$ & $18.8 \pm 4.1$ & $5.3 \pm 1.9$ & $26.2 \pm 4.8$ & $29.9 \pm 5.5$ \\
\hline & Major & $23.5 \pm 3.7$ & $2.8 \pm 1.9$ & $4.2 \pm 2.5$ & $0.7 \pm 0.7$ & $7.0 \pm 2.3$ & $8.8 \pm 2.4$ \\
\hline \multirow[t]{2}{*}{ CPL } & All & $82.7 \pm 12.2$ & $7.2 \pm 3.6$ & $16.5 \pm 3.7$ & $7.3 \pm 2.4$ & $22.3 \pm 5.3$ & $29.3 \pm 9.3$ \\
\hline & Major & $15.5 \pm 3.3$ & $0.83 \pm 0.8$ & $0.53 \pm 0.7$ & $1.0 \pm 0.9$ & $8.6 \pm 2.8$ & $4.5 \pm 1.7$ \\
\hline
\end{tabular}


a.
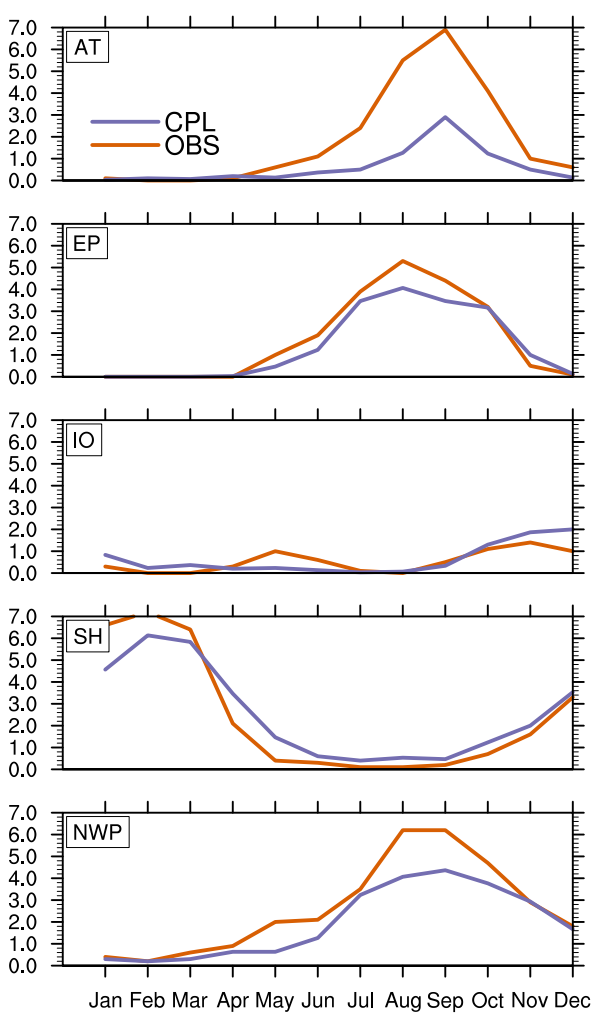

b.

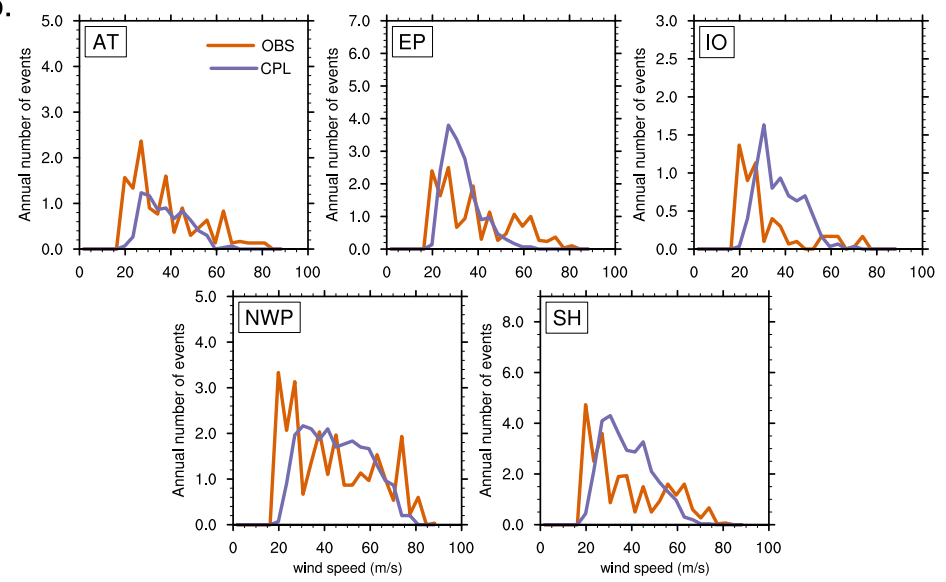

C.

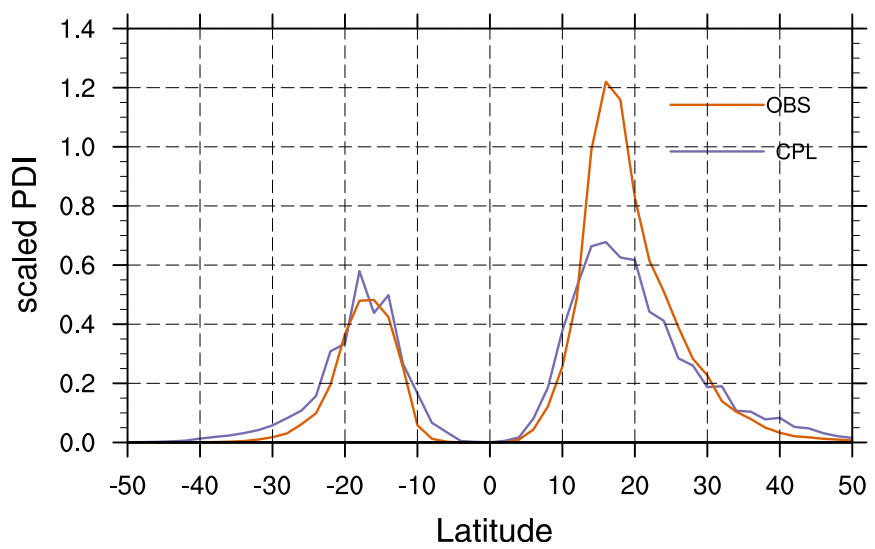

FIG. 3. (a) Long-term mean TC seasonality in the observational records (orange) during 1985-2014 and the 30-yr CESM coupled simulation (blue) in AT, EP, IO, SH, and NWP. The $x$ axis is the month of the year, and the $y$ axis is average TC count. (b) Comparisons of average TC intensity distribution in different TC basins in the observational records (orange) and the CESM coupled simulation (blue). (c) Latitudinal distribution of average annual TC PDI in the observations (orange) and CESM coupled simulation (blue). PDI is scaled by $1 \times 10^{-11}$.

modeled PDI is larger near the equator and at the higher latitudes, because the modeled TCs form closer to the equator and travel to higher latitudes than in the observations.

\section{b. Ocean's response to TCs}

In this section, we first analyze TCs' impact on annual and seasonal mean SST and subsurface potential temperature patterns [section $3 b(1)]$. We then examine the ocean's dynamic responses to TCs [section 3b(2)]. Last, we discuss TC-induced ocean meridional heat transport [section 3b(3)] and ocean heat uptake [section 3b(4)] on seasonal to interannual time scales.

\section{1) OCEAN TEMPERATURE ResPONSES TO TCS}

Figure 4 shows the vertical profile of the long-term mean global average TC-induced ocean potential temperature anomalies. The annual average response is characterized by an average surface cooling of $0.08^{\circ} \mathrm{C}$ and a subsurface warming that maximizes at $0.05^{\circ} \mathrm{C}$ at 65-m depth (Fig. 4a). The structure of the vertical profile, which suggests the effect of TC-induced vertical mixing, is robust throughout the year. The magnitudes of the temperature anomalies are stronger in boreal summer (July-November; Fig. 4b) than in boreal winter (December-June; Fig. 4c). In this subsection, we will examine the spatial patterns of the surface and subsurface temperature anomalies. In the rest of the paper, the Northern Hemisphere summer is defined as JulyNovember, and winter is defined as December-June. The opposite is true for the Southern Hemisphere.

\section{(i) $S S T$}

Figure 5 shows the difference of long-term mean average SST over the 27 years between OCN_TC and OCN_FILT, indicating TC-induced SST anomalies. On the annual average (Fig. 5a), TCs tend to cool the ocean surface. The cooling is mainly due to turbulent mixing, 

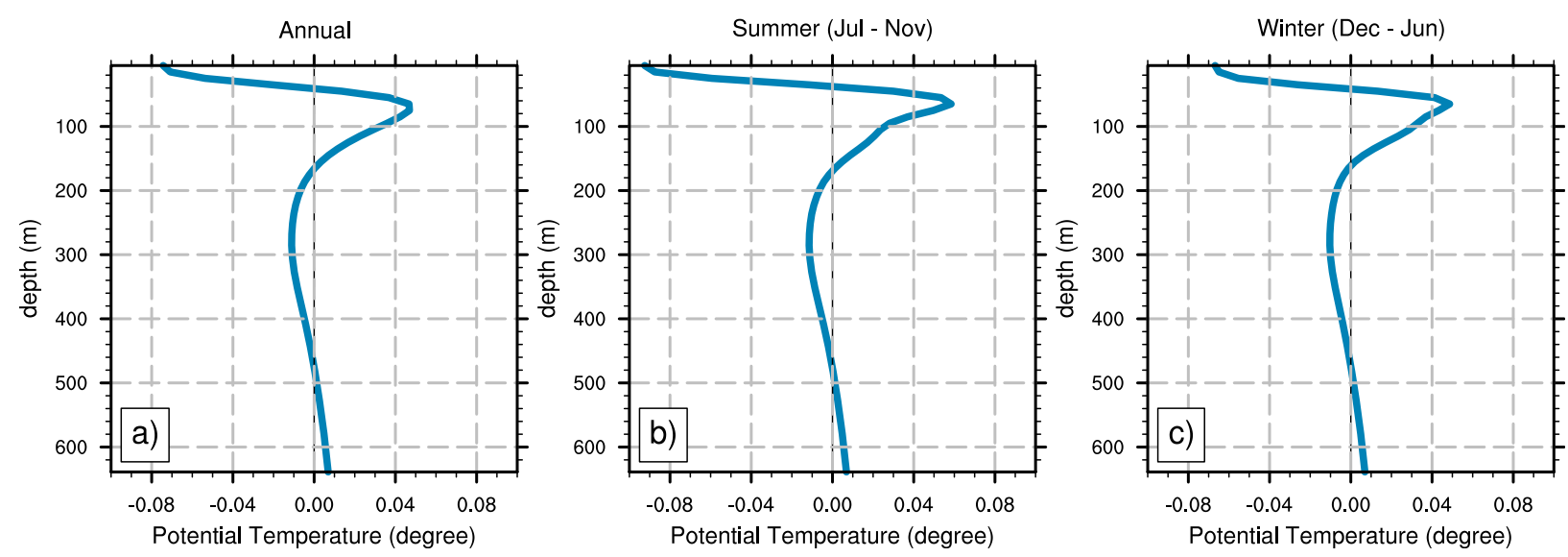

FIG. 4. Vertical profile of average TC-induced potential temperature anomalies $\left({ }^{\circ} \mathrm{C}\right)$ for (a) annual average, (b) boreal summer $(\mathrm{July}-$ November), and (c) boreal winter (December-June).

surface heat loss, and Ekman pumping (Ginis 2002; Jullien et al. 2012). The maximum cooling occurs in the northwestern Pacific basin, reaching about $-0.5^{\circ} \mathrm{C}$. TCinduced surface cooling is more significant during the TC season in the respective hemispheres (Figs. 5b,c). The major TC basins experience warming during the respective winter season in each hemisphere, and the warming is most significant at the midlatitudes around $40^{\circ}-60^{\circ} \mathrm{N}$ in the Northern Hemisphere. This pattern is similar to the modeling results shown in Vincent et al. (2013).

The wintertime warming anomalies are likely due to seasonal variations in the ocean mixed layer depth: Thermocline heating during the TC season occurs when the mixed layer is relatively shallow compared to winter, and some of the heat will reenter the ocean mixed layer during seasonal thermocline deepening and eventually be transferred back to the atmosphere (Jansen et al. 2010). This heat loss can happen both locally and remotely, as the anomalous heat may be transported elsewhere by ocean currents. The wintertime surface warming in the Southern Hemisphere (during JulyNovember) is much weaker compared to the Northern Hemisphere (during December-June), which may be attributed to the relatively weaker TC-induced vertical mixing and heat uptake (Figs. 5c, 6c). Differences in ocean currents may also play a role, as the poleward upper-ocean heat transport is greater in the Northern Hemisphere, and the subsurface warming can be transported to higher latitudes where the mixed layer depth experiences larger seasonal variations. Some heat in the Southern Hemisphere could also be transported to the Northern Hemisphere. In the Northern Hemisphere midlatitudes, TC-induced wintertime SST anomalies exhibit an anomalous dipole pattern (Fig. 5c), which tends to reduce the meridional SST gradient and may have implications for the midlatitude winter storm tracks (e.g., Graff and LaCasce 2012).

\section{(ii) Subsurface temperature responses}

Figure 6 shows TC-induced long-term mean ocean subsurface temperature anomalies averaged between 50 and $100 \mathrm{~m}$, which represents the depth of maximum global average warming (Fig. 4). On the annual mean (Fig. 6a), the subsurface warming can be seen in all the major TC basins, and the spatial pattern is in accordance with the surface cooling (Fig. 5a). The subsurface warming during the TC season is stronger in Northern Hemisphere basins (Fig. 6b) than in the Southern Hemisphere (Fig. 6c). Persistent subsurface warming can also be seen in the equatorial Indian Ocean and equatorial eastern Pacific.

The equatorial Pacific is critical for tropical ocean heat uptake and transport, featuring the upwelling branch of the Pacific subtropical cells, the Equatorial Undercurrent, equatorial waves, etc. To take a closer look at the TC-induced subsurface warming in the equatorial Pacific, we analyze the depth-zonal cross section of the TC-induced long-term mean anomalous ocean potential temperature averaged over $5^{\circ} \mathrm{S}-5^{\circ} \mathrm{N}$ across $120^{\circ} \mathrm{E}-90^{\circ} \mathrm{W}$. Figure 7 shows the monthly mean responses for all months starting in July. The eastern Pacific main thermocline shows much stronger and persistent anomalous warming compared to the western Pacific. Starting in July, TC-induced heat anomalies begin to emerge in the western Pacific. The heat is then transported to the eastern Pacific and continues to accumulate during the following season by equatorial Kelvin waves or by the Equatorial Undercurrent (animation in supplemental material). The warming is most significant from September to January when the thermocline exhibits stronger stratification. 

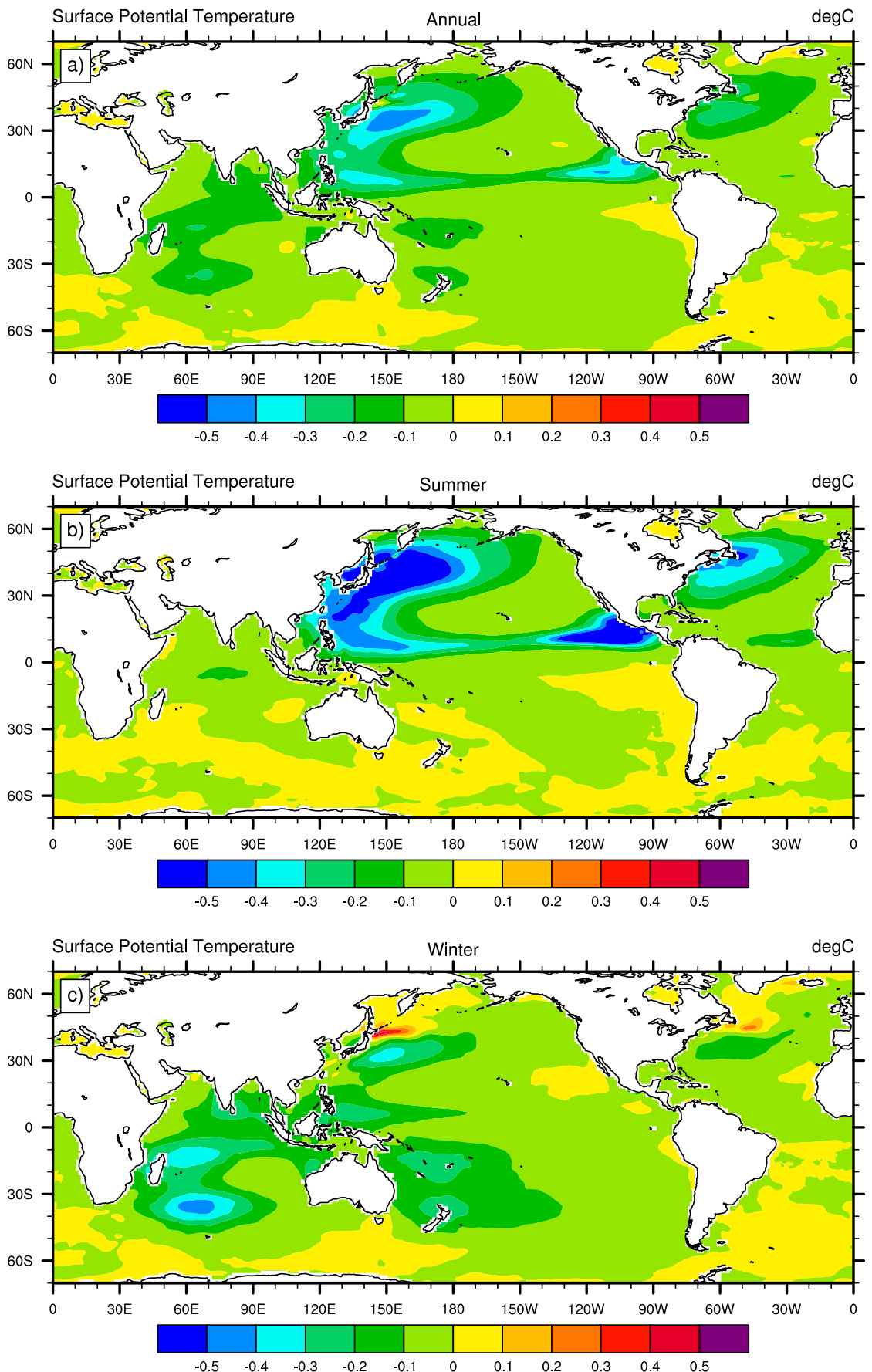

FIG. 5. Long-term mean (a) annual, (b) boreal summer (June-November), and (c) boreal winter (December-May) SST difference $\left({ }^{\circ} \mathrm{C}\right)$ between OCN_TC and OCN_FILT.

Figure 8 shows the depth-meridional cross section of the long-term mean annual and seasonal zonal-average potential temperature anomalies in the Indian Ocean $\left(50^{\circ} \mathrm{S}-30^{\circ} \mathrm{N}, 35^{\circ}-100^{\circ} \mathrm{E}\right)$, eastern Pacific $\left(50^{\circ} \mathrm{S}-60^{\circ} \mathrm{N}\right.$, $\left.180^{\circ}-100^{\circ} \mathrm{W}\right)$, Atlantic $\left(50^{\circ} \mathrm{S}-60^{\circ} \mathrm{N}, 170^{\circ} \mathrm{W}-360^{\circ}\right)$, and western Pacific $\left(50^{\circ} \mathrm{S}-60^{\circ} \mathrm{N}, 120^{\circ}-170^{\circ} \mathrm{E}\right)$. Generally, in each basin, TCs cause warm temperature anomalies just below the seasonal mixed layer during the TC season in the respective hemispheres. The warm anomalies then travel along the potential temperature isotherms. In the Indian Ocean, the most significant warming occurs in the equatorial region $\left(10^{\circ} \mathrm{S}-10^{\circ} \mathrm{N}\right)$, as the TC-induced warm 



FIG. 6. As in Fig. 5, but for ocean subsurface temperature difference averaged between 50 and $100 \mathrm{~m}$.

anomalies during the summer season in each hemisphere converge toward the equator (supplemental animation). The subsurface warming is more pronounced in the southern Indian Ocean during boreal winter (December-June). In the eastern Pacific, TC-induced warm anomalies travel downward and equatorward along the isotherm following the subtropical cell, and the heat is accumulated within the upwelling region of the eastern Pacific convergence zone. The subsurface warm anomalies are mainly from the northeastern Pacific, but a weak temperature anomaly can also be seen in the southeastern Pacific during boreal winter. TCinduced temperature anomalies are much weaker in the Atlantic basin compared with other basins. This is likely 

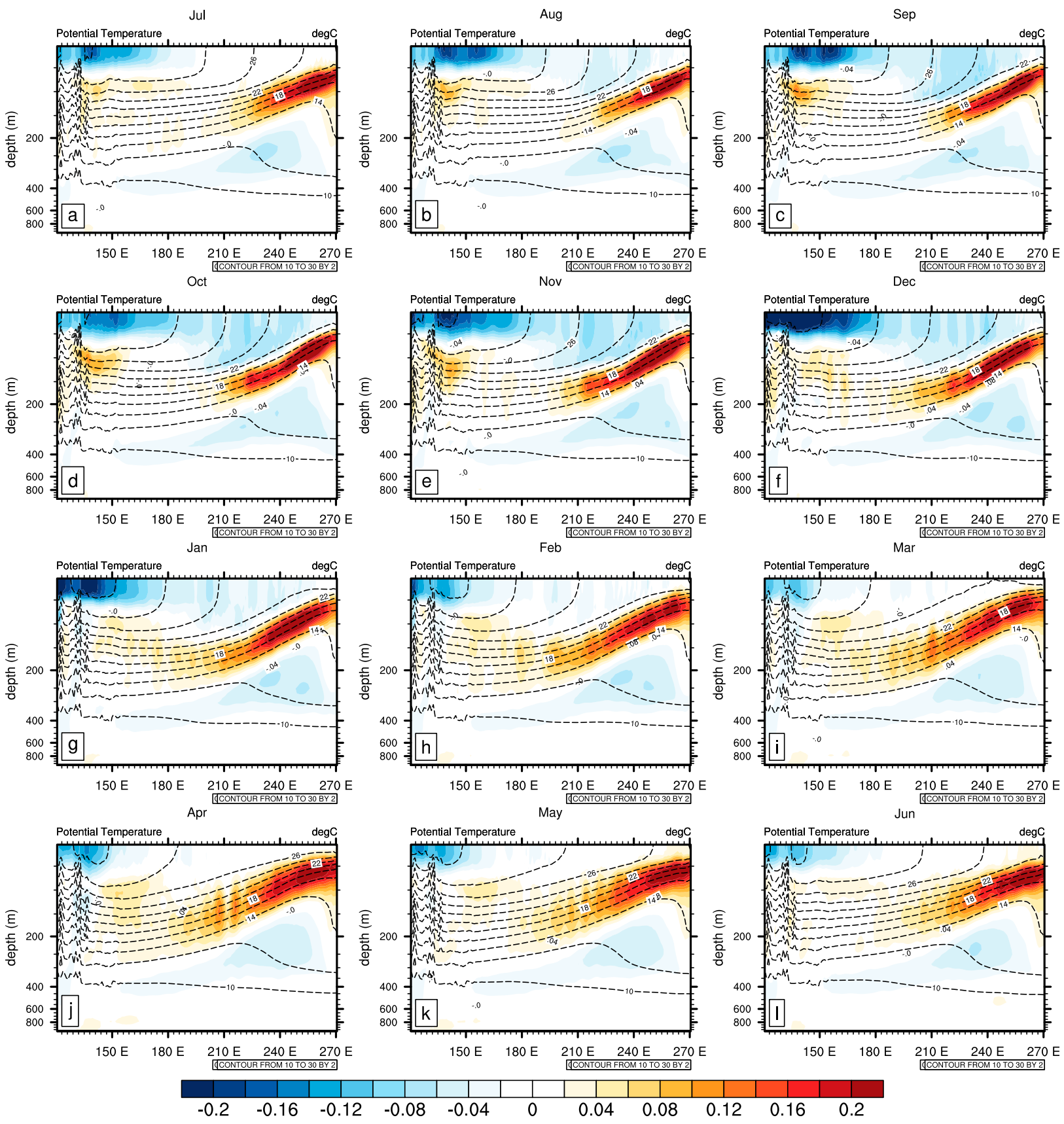

FIG. 7. Depth-zonal cross section of long-term monthly mean equatorial potential temperature difference (colors; $\left.{ }^{\circ} \mathrm{C}\right)$ averaged between $5^{\circ} \mathrm{S}$ and $5^{\circ} \mathrm{N}$ starting in July. The dashed contours represent the isotherms of the potential temperature in OCN_TC $\left({ }^{\circ} \mathrm{C}\right)$.

owing to the largely underestimated TC activity in this basin.

The western Pacific exhibits many unique features. Most of the TC-induced temperature anomalies occur in the North Pacific. The most significant subsurface warming can be seen within the subtropics $\left(10^{\circ}-30^{\circ} \mathrm{N}\right)$ and midlatitudes $\left(35^{\circ}-50^{\circ} \mathrm{N}\right)$, and the midlatitude warming can reach down to $1000-\mathrm{m}$ depth along the isotherms. During the Northern Hemisphere summer (June-November), vertical mixing causes pronounced warming below the ocean mixed layer. In the boreal winter months, the subsurface heat anomalies are greatly reduced, corresponding to the seasonal deepening of the ocean mixed layer. Meanwhile, the midlatitude region around $30^{\circ}-35^{\circ} \mathrm{N}$ experiences anomalous cooling from the surface down to about $400 \mathrm{~m}$. To better 

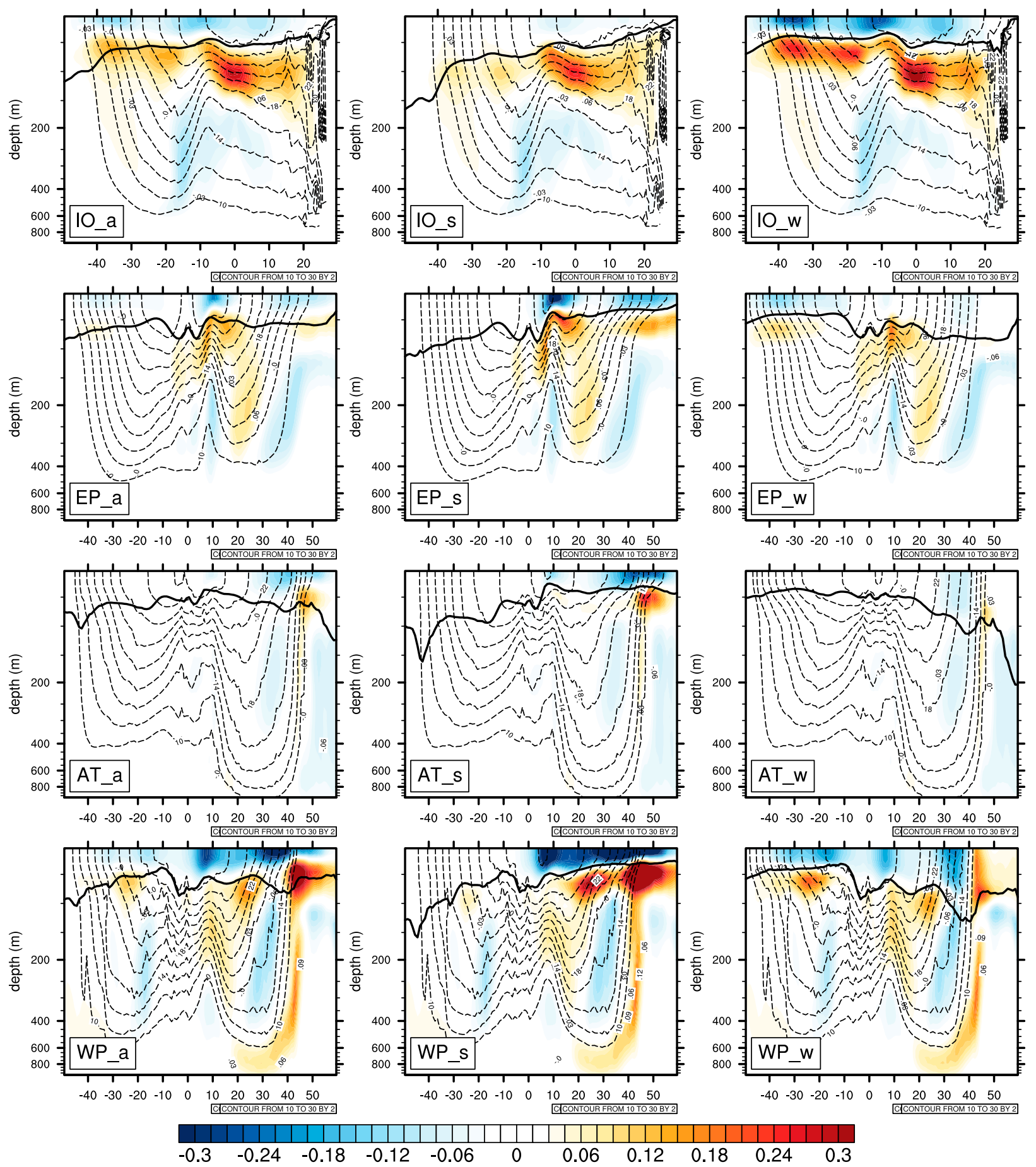

FIG. 8. Depth-meridional cross section of long-term mean subsurface potential temperature difference (colors; $\left.{ }^{\circ} \mathrm{C}\right)$ in the (top) IO, (top middle) EP, (bottom middle) Atlantic, and (bottom) western Pacific for (left) annual, (center) boreal summer (June-November), and (right) boreal winter (December-May). The thin dashed contours represent the isotherms of potential temperature in OCN_TC $\left({ }^{\circ} \mathrm{C}\right)$. The thick solid contours indicate the mixed layer depth in OCN_TC (m).

understand the associated physical processes in the northwestern Pacific, we analyze the monthly evolution of the long-term mean TC-induced thermodynamic anomalies in more detail (Fig. 9), with a special focus on the role of late-winter ocean dynamics.

During the northwestern Pacific TC main season from August to November (Figs. 9b-e), the enhanced vertical 

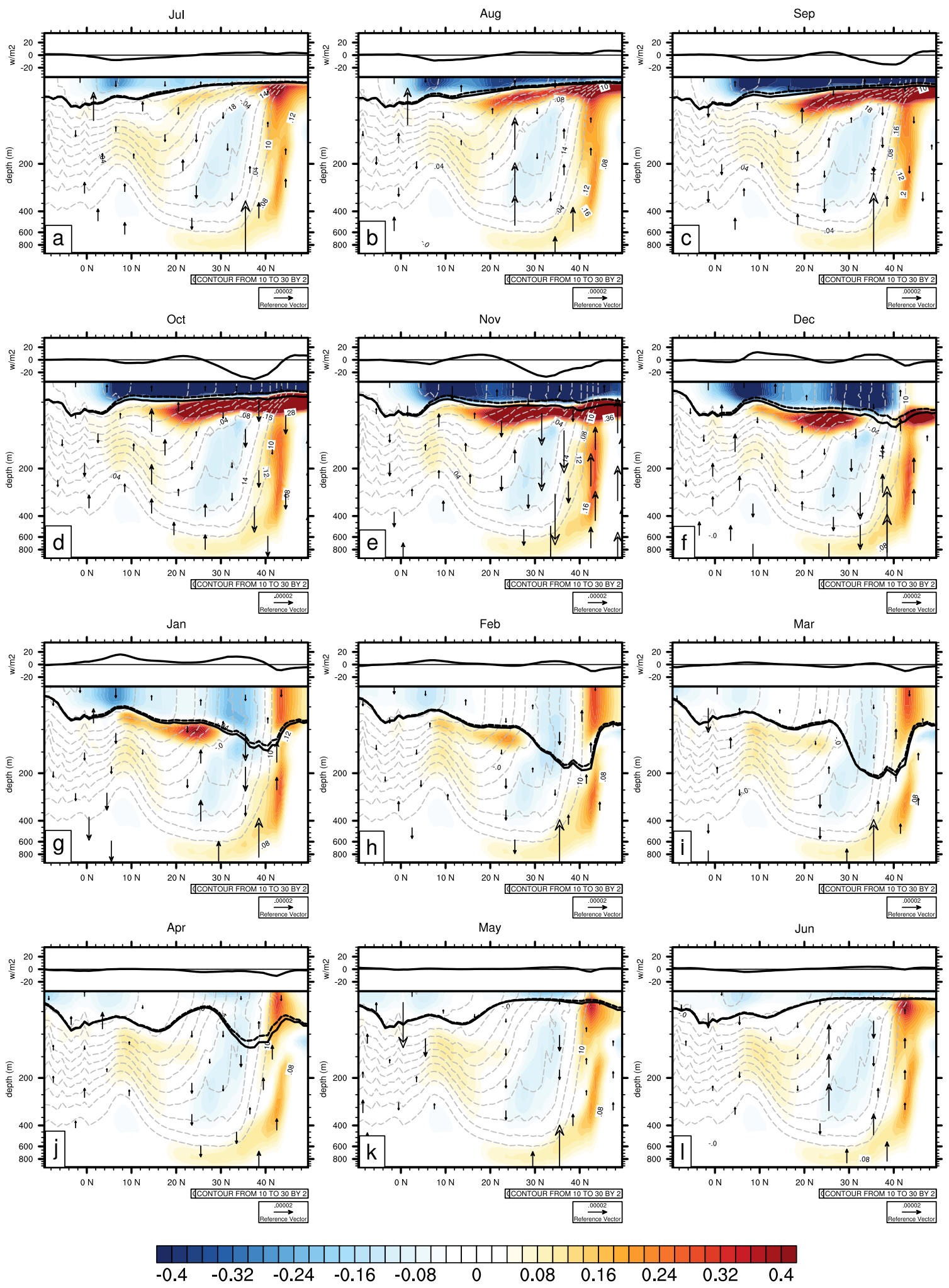

FIG. 9. Monthly mean meridional cross section of the TC-induced anomalies in the NWP basin starting in July. The $X-Y$ plot on top of each panel shows the zonal-average surface heat flux anomalies induced by TCs $\left(\mathrm{W} \mathrm{m}^{-2}\right)$. Positive values indicate heat goes into the ocean. For the bottom plot in each panel, the colored contours represent anomalous potential temperature $\left({ }^{\circ} \mathrm{C}\right)$; the black vectors indicate anomalous vertical motion $\left(\mathrm{m} \mathrm{s}^{-1}\right)$; the dashed gray contour lines represent the isotherms in OCN_TC $\left({ }^{\circ} \mathrm{C}\right)$; the thick solid black lines indicate the mixed layer depth in OCN_TC; and the thick dashed black lines are the mixed layer depth in OCN_FILT (m). 
mixing results in strong near-surface cooling and subsurface warming, spanning from the subtropics to $\sim 50^{\circ} \mathrm{N}$. The subtropical region at about $15^{\circ}-25^{\circ} \mathrm{N}$ features anomalous upward motion, which may be partly attributed to enhanced upwelling under TCs as well as changes in the large-scale circulation. For the long-term mean average, the midlatitudes from $25^{\circ}$ to $45^{\circ} \mathrm{N}$ have the largest TC-induced surface heat loss from the ocean. From November to December (Figs. 9e,f), the midlatitudes at $35^{\circ}-40^{\circ} \mathrm{N}$ experience the earliest and fastest deepening of the ocean mixed layer. As a result, the heat is reabsorbed by the mixed layer and partially advected meridionally to adjacent latitudes. By December, the subsurface warming at this latitude has faded, while the near-surface cooling remains. Meanwhile, the latitudes with TC-induced surface cooling correspond to anomalous surface heat gain into the ocean, indicative of the recovery of the cold wake through surface heat flux adjustment.

In the late winter, the midlatitude ocean is characterized by outcropped isotherms in the ventilated thermocline with largely reduced vertical stratification (Fig. 9f). Under such conditions, the surface forcing may directly impact the subsurface through thermocline ventilation (Williams 1989). As the mixed layer continues to deepen through March (Figs. 9f-i), more subsurface warming is lost to the mixed layer, while the remaining anomalies at the base of the mixed layer are ventilated along the isotherms by large-scale subduction at the edge of the subtropical gyre: The anomalous warming in the subtropical region converges back to the tropics along the returning branch of the subtropical cell, and the anomalous cooling at $\sim 35^{\circ} \mathrm{N}$ travels downward and southward to about 300-m depth; the heat anomalies in the higher latitudes about $39^{\circ}-43^{\circ} \mathrm{N}$ are pumped down to $\sim 600 \mathrm{~m}$ and reach $1000-\mathrm{m}$ depth along the shallow overturning cell (see also the supplemental animation). The warm anomalies within the mixed layer north of $40^{\circ} \mathrm{N}$ remain throughout the winter and spring season, which suggests that this warming is due to zonal advection by the Kuroshio (see also Fig. 6).

The remaining effect of northwestern Pacific TCs after the main season can be implied from Figs. 9j-1. As the mixed layer shoals in April (Fig. 9j), the surviving heat anomalies remain in the permanent thermocline. The thermodynamic features and the formation processes of this cold water mass are consistent with the Subtropical Mode Water formation (Hanawa and Talley 2001), suggesting that the modeled TCs may influence the properties of the Subtropical Mode Water at 100300-m depth, with important implications for ocean dynamics and primary production. In addition, the warm anomalies in the higher latitudes north of $40^{\circ} \mathrm{N}$ increase the buoyancy of the subsurface water, which may affect ocean convection and induce changes in meridional circulation in the western Pacific. Furthermore, the heat anomalies pumped down from this high latitude tend to travel along the returning branch of the overturning cell, which can affect the tropical ocean on interannual to decadal time scales (Fedorov et al. 2010; Sriver and Huber 2010).

\section{2) OCEAN DYNAMIC RESPONSES TO TCS}

\section{(i) Ocean mixed layer}

TCs can enhance upper-ocean mixing and therefore alter the depth of the ocean mixed layer. We examine TCs' impact on the long-term mean ocean mixed layer depth (Fig. 10). Here the mixed layer depth is defined as in Large et al. (1997), which is the depth at which the local buoyancy gradient equals the maximum buoyancy gradient referenced to the surface. On annual average (Fig. 10a), the pattern of the anomalous mixed layer depth is consistent with that of anomalous SST (Fig. 5), with increased mixed layer depth in all of the major TC basins. The anomalies are larger during the TC season in the subtropics during the respective hemispheric TC season (Figs. 10b,c), owing to the direct forcing of transient TC mixing. The maximum mixed layer deepening is found at the upstream Kuroshio Extension region southeast of Japan, which peaks in the winter season with a maximum of $18-\mathrm{m}$ anomaly.

The largest mixed layer depth anomalies take place at times when the ocean mixed layer experiences the largest seasonal variation, such as in November and December when the seasonal mixed layer begins to deepen (Figs. 9e,f), and in April when the mixed layer begins to shoal (Fig. 9j). During these time periods, the mixed layer variation is sensitive to surface wind forcing and heat loss associated with air-sea exchange. As can be seen in Fig. 9, two mechanisms can contribute to the enhanced mixing: 1 ) enhanced surface cooling related to late-season TC events and 2) quick surface heat loss when the Kuroshio transports anomalous warm water poleward to this region (Figs. 6, 9g). The TCs' effect contributes to the onset and extent of the seasonal mixed layer deepening and delays the spring shoaling. Similar responses are also found in the North Atlantic basin.

\section{(ii) Ocean circulation}

Studies show that TCs are efficient mixers of the upper ocean, representing localized transient diapycnal mixing on the strongly stratified tropical thermocline. On seasonal to annual time scales, TCs cause vertical mixing at the upper ocean near the bottom of the mixed layer. This mixing process injects heat into the ocean that 

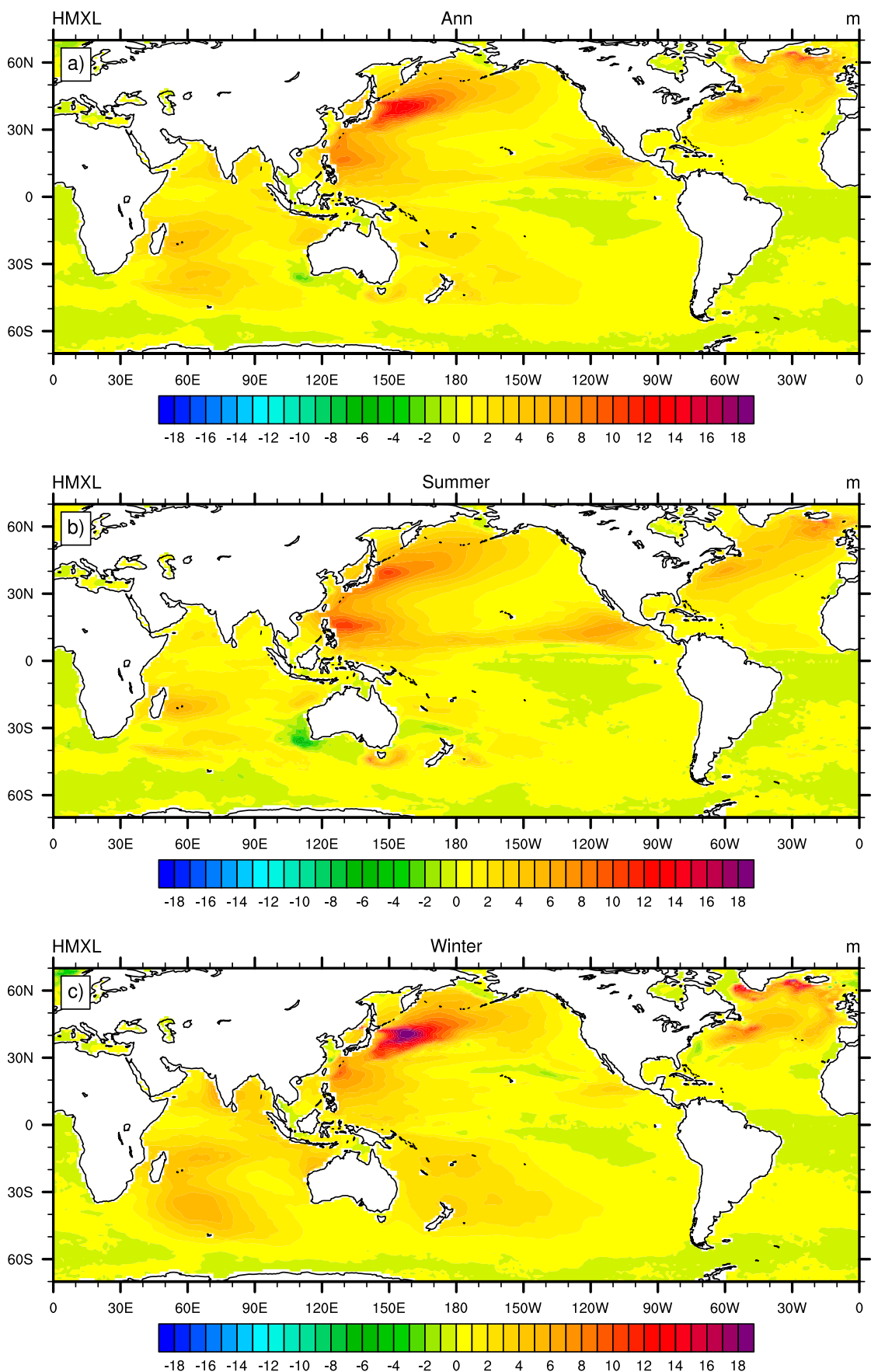

FIG. 10. Long-term mean (a) annual, (b) summer (June-November), and (c) winter (December-May) ocean mixed layer depth differences (m).

subsequently gets transported by the ocean currents as well as radiated downward into the ocean interior by the near-inertial waves. On longer time scales, this TCinduced mixing is shown to be important for sustaining the ocean meridional overturning (Jansen and Ferrari 2009; Boos et al. 2004; Korty et al. 2008; Sriver and
Huber 2010). Here we examine the potential effect of TCs on ocean circulation. The annual average meridional circulation and the associated vertical motion is shown in Fig. 11. The ocean model can simulate the global and Atlantic overturning structure and the associated vertical motion reasonably well (Figs. 11a,c). On 

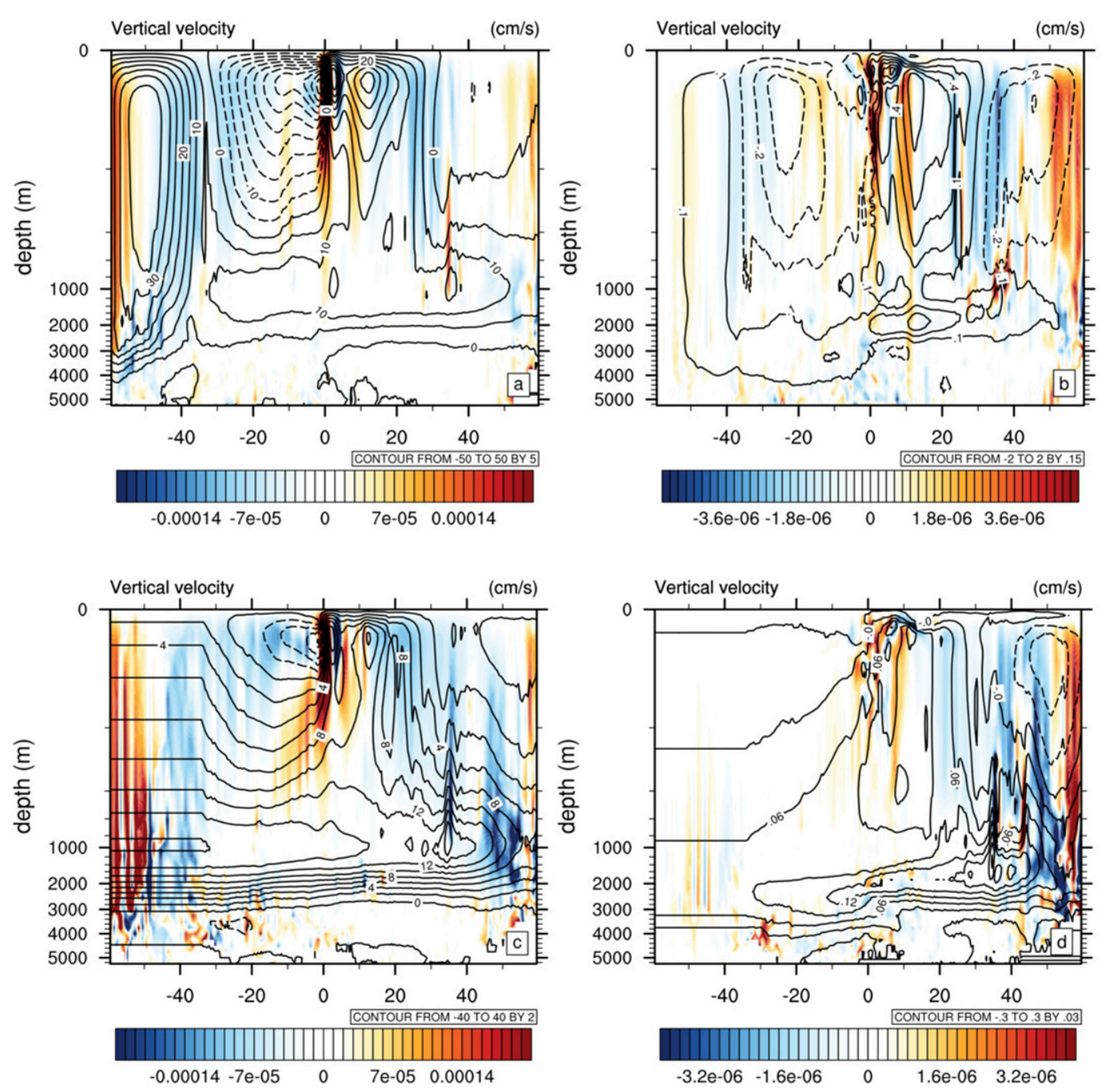

FIG. 11. Meridional cross section of (a),(b) global and (c),(d) Atlantic long-term mean average vertical velocity (colors; $\mathrm{m} \mathrm{s}^{-1}$ ) and MOC (contours; Sv) in (left) OCN_TC and (right) the difference between OCN_TC and OCN FILT.

global average, TCs in the model strengthen the overturning cells in both hemispheres. The global average maximum meridional overturning is increased by about $3 \%$. A similar response is also seen in the North Atlantic basin (Figs. 11c,d), though the changes are much smaller, which may be partly owing to the lack of TC activity in this basin. The maximum overturning is increased by about $1 \%$ in the Atlantic. Corresponding to the strengthened overturning is enhanced upwelling in the tropical convergence zone and subpolar gyre center and strengthened subduction in the subtropical gyre center.

Figure 12 shows the long-term mean climatology of the barotropic streamfunction in the OCN_TC run (Figs. 12a-c) and TC-induced anomalies (Figs. 12d,f), representing the strength of the ocean gyre circulations.
On annual average, the modeled TCs tend to strengthen the major circulation gyres, consistent with the meridional vertical motion in Fig. 11. The maximum change is in the Northern Hemisphere subtropical gyre during boreal summer, with a maximum increase of $\sim 2.5 \mathrm{~Sv}(1 \mathrm{~Sv} \equiv$ $10^{6} \mathrm{~m}^{3} \mathrm{~s}^{-1}$; Fig. 12e).

The strengthened subtropical gyre is likely attributed to TCs' contribution to the mean wind stress (Fig. 13). We find that TCs can enhance the average surface wind stress in the main TC basins (Fig. 13c). The maximum increase of wind stress occurs in the northwestern Pacific, where most of the strong TCs take place. On the latitudinal average, the maximum TC-induced wind stress anomaly is found at the Northern Hemisphere midlatitude, which accounts for about $4 \%$ of the mean value. The increased wind stress 

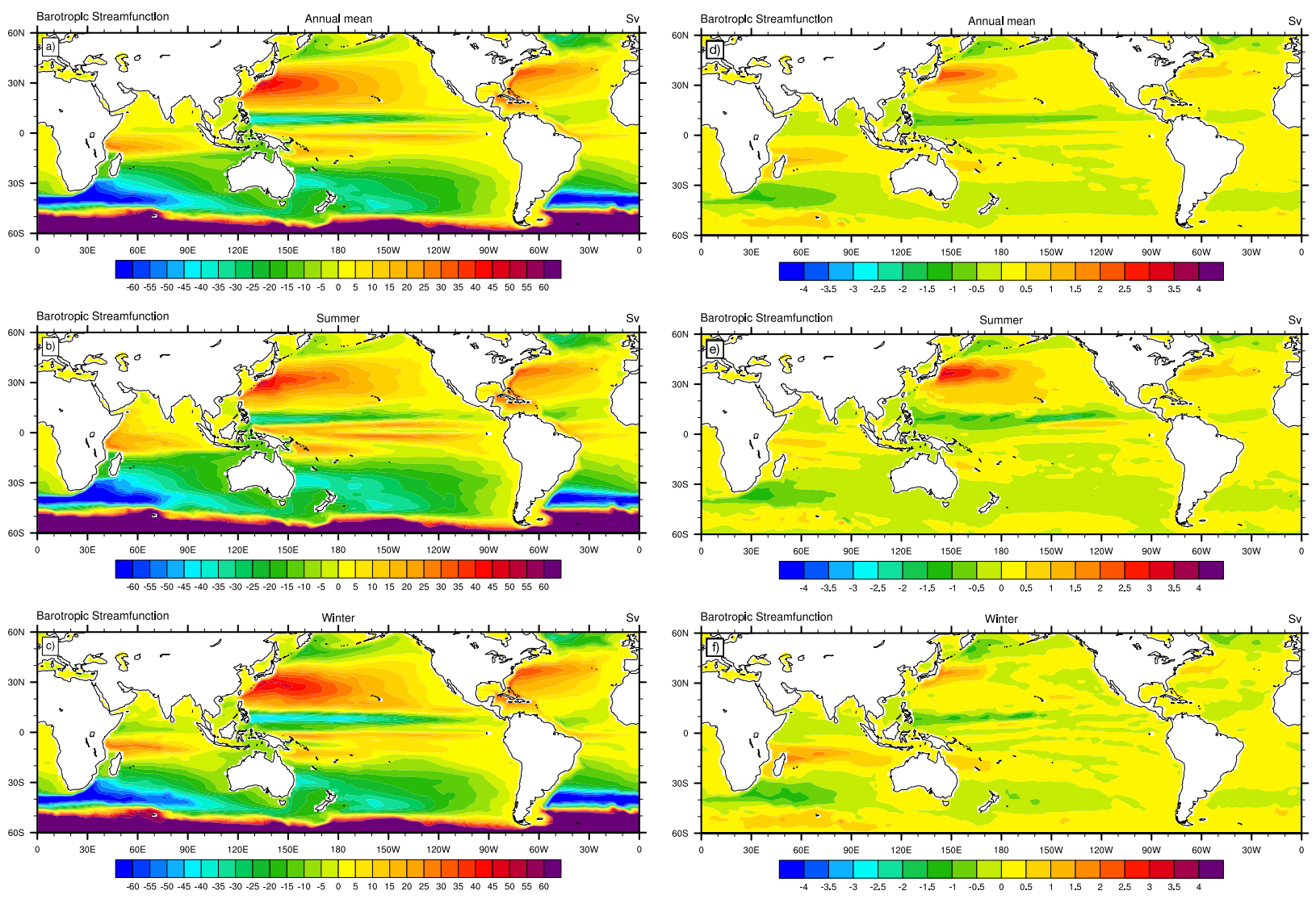

FIG. 12. (left) Climatological barotropic streamfunction in OCN_TC and (right) the differences between OCN_TC and OCN_FILT (Sv). Shown are the (a),(d) annual mean; (b),(e) summer (June-November) mean; and (c),(f) winter (December-May) mean.

and wind curl helps strengthen the wind-driven gyre circulation.

\section{3) TC-INDUCED MHT}

We examine TCs' impact on the meridional ocean heat transport (MHT; Fig. 14). The patterns of the annual average global total MHT in the two ocean simulations are consistent with observations and other ocean modeling studies (e.g., Jansen and Ferrari 2009; Maltrud and McClean 2005), though the magnitude of the peak transport $(\sim 1.5 \mathrm{PW})$ is smaller than observational estimates of 1.7 PW (Ganachaud and Wunsch 2000; Trenberth and Caron 2001). The model also simulates a small net northward transport at the equator.

In general, the modeled TCs amplify the background meridional heat transport patterns. The largest changes are at the latitudes of peak TC activity (Fig. 3c). The peak anomalous poleward MHT is $0.035 \mathrm{PW}$ in the Northern Hemisphere and 0.018 PW in the Southern Hemisphere. The result is similar to a recent modeling study (Vincent et al. 2013), and it is significantly smaller than earlier estimates (Emanuel 2001; Sriver and Huber 2007). The Northern Hemisphere TC-induced maximum poleward transport is only about $2.5 \%$ of the hemispheric peak MHT. However, when comparing with previous estimates, it is important to keep in mind that here we are using TCs from a coupled model simulation rather than from observations. As is discussed in section $3 \mathrm{a}$, the coupled model has fewer and weaker TCs in the North Atlantic, and the Northern Hemisphere maximum PDI is only $55 \%$ of the observations (see Fig. 3c). In addition, TCs' impact on MHT can also be affected by the relatively coarse ocean horizontal grid resolution used in this study.

TC-induced meridional heat convergence/divergence can be inferred from the slope of the curves in Fig. 14. If we define TC-induced MHT anomaly as $\triangle \mathrm{MHT}$, then when the slope of $\Delta \mathrm{MHT}(\partial \Delta \mathrm{MHT} / \partial x)$ and the slope of the background MHT ( $\partial \mathrm{MHT} / \partial x)$ have the same (opposite) sign, TCs amplify (reduce) the background convergence/divergence. For example, when the background northward MHT diverges $(\partial \mathrm{MHT} / \partial x>0)$, then locations where $\partial \Delta \mathrm{MHT} / \partial x>0$ have enhanced divergence, and locations where $\partial \Delta \mathrm{MHT} / \partial x<0$ have anomalous convergence.

We find that TCs' impact on ocean meridional heat convergence can be attributed both to TC-induced 

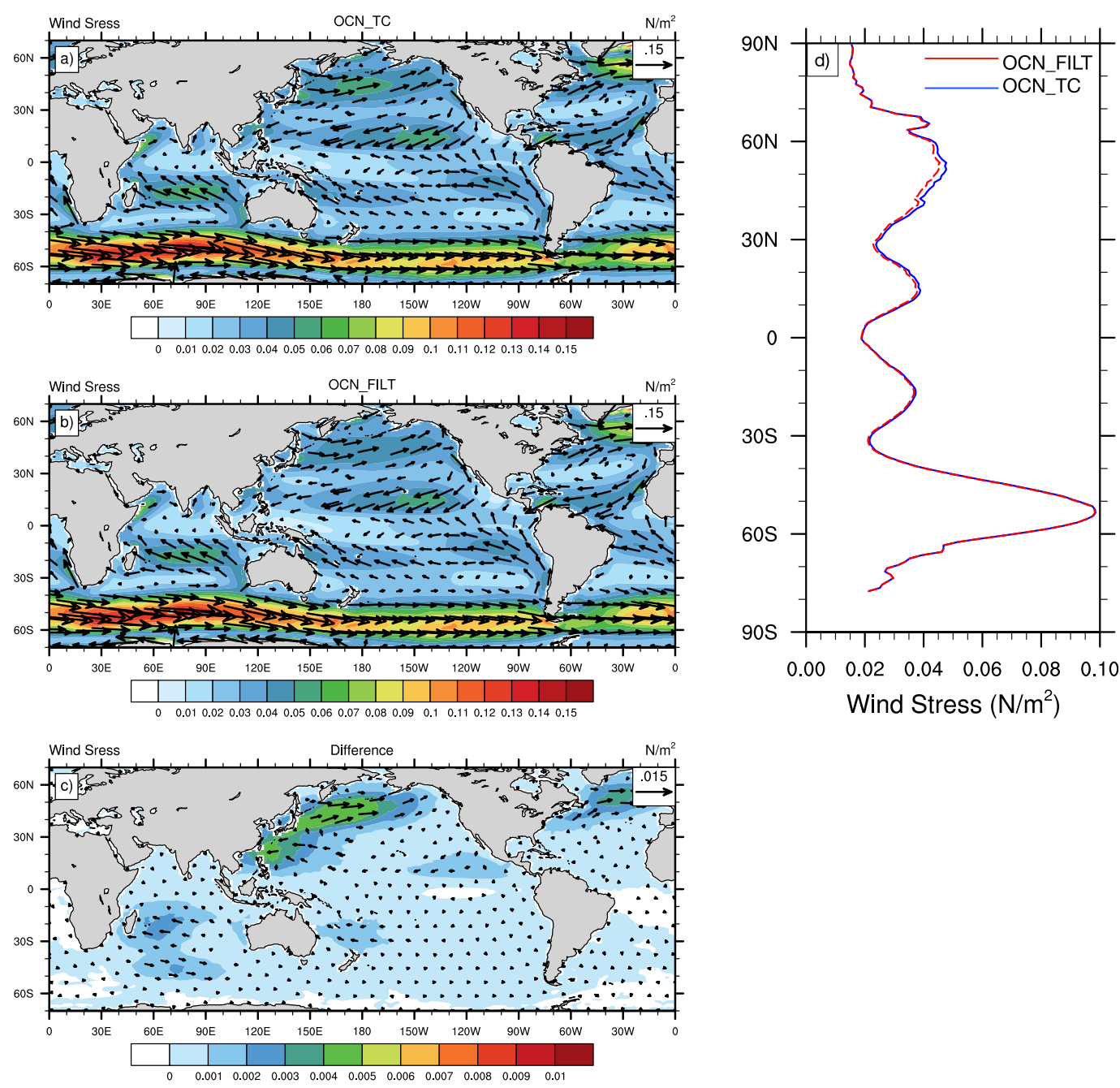

FIG. 13. Long-term mean surface wind stress (colors; $\mathrm{N} \mathrm{m}^{-2}$ ) in (a) OCN_TC, (b) OCN_FILT, (c) their differences, and (d) the zonal mean wind stress. The colors in (a)-(c) show the magnitude of the wind stress, and the vectors indicate the direction.

ocean heat anomalies and changes in ocean dynamics. Anomalous heat converges at $2^{\circ} \sim 12^{\circ} \mathrm{S}$ near the equator due to equatorial upwelling of TC-induced warming (see Fig. 8). Divergence mainly occurs at $2^{\circ} \mathrm{S}-20^{\circ} \mathrm{N}$ and $12^{\circ}-$ $25^{\circ} \mathrm{S}$, with the maximum at the latitudes of peak TC activity $\left(15^{\circ}-20^{\circ} \mathrm{N}\right.$ and $\left.12^{\circ} \sim 25^{\circ} \mathrm{S}\right)$. The general divergence from $2^{\circ} \mathrm{S}$ to $20^{\circ} \mathrm{N}$ and convergence at $25^{\circ}-45^{\circ} \mathrm{N}$ indicates the effect of enhanced North Hemisphere subtropical overturning. Likely, the small divergence zone at $45^{\circ}-55^{\circ} \mathrm{N}$ is due to the strengthened subpolar gyre. Heat convergence north of $55^{\circ} \mathrm{N}$ and south of $25^{\circ} \mathrm{S}$ is consistent with the anomalous warming associated with the poleward transport of warm anomalies by the western boundary current (e.g., Figs. 5, 6).

The pattern of the anomalous MHT is different from previous ocean modeling studies of Vincent et al. (2013) and Jansen and Ferrari (2009), in which a maximum near-equator ocean heat convergence is found at $0^{\circ}-$ $20^{\circ} \mathrm{N}$. In this model, the enhanced northward crossequator heat transport overwhelms the equatorial heat convergence in this region. The difference may be partly attributed to the differences in the latitudinal distribution of TCs between the model and observations. Here the model simulates more TC mixing closer the equator (see Fig. 3c), where strong stratification may further amplify TC-induced vertical diffusivity. Jansen and Ferrari (2009) found that the pattern of the heat transport is sensitive to the latitudinal band of TC mixing, and when increased diffusivity is applied over the tropical ocean with no equatorial gap, the resulting $\triangle \mathrm{MHT}$ tends to enhance the background MHT and has a pattern similar to Fig. 14. 


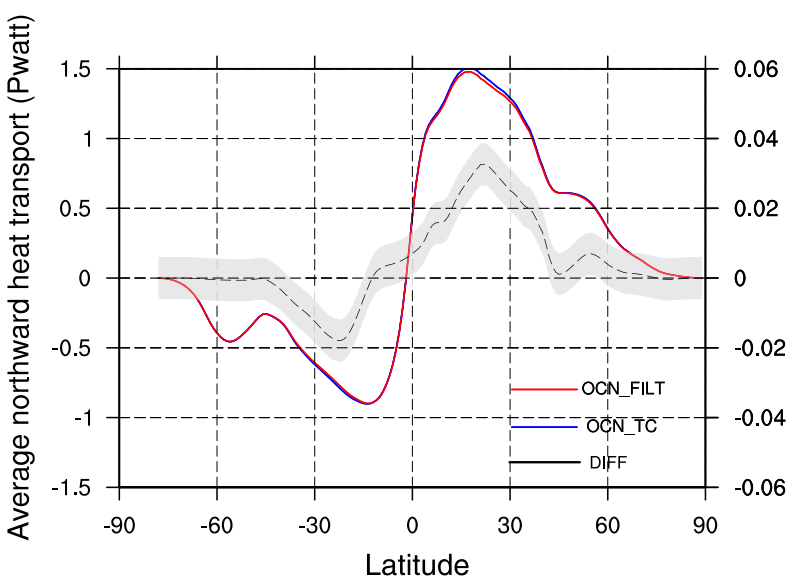

FIG. 14. Long-term mean meridional total ocean heat transport (PW) in the two models (blue and red solid lines, left $y$ axis) and TC-induced anomalies (black dashed line, right $y$ axis). The gray shading indicates the $90 \%$ confidence level of the TC-induced anomalies.

\section{4) TC-INDUCED OHU}

In this section, we estimate TC-induced ocean heat uptake (OHU) and analyze its interannual variability. Here OHU is defined the same as in $\mathrm{Li}$ and Sriver (2016):

$$
\mathrm{OHU}(t)=\iiint_{-d}^{\mathrm{XMXL}} \rho C \Delta T d h d A
$$

where $\rho$ is the density of seawater $\left(1020 \mathrm{~kg} \mathrm{~m}^{-3}\right), C$ is the heat capacity $\left(3900 \mathrm{~J} \mathrm{~kg}^{-1}{ }^{\circ} \mathrm{C}^{-1}\right)$, and $\Delta T$ is the ocean temperature difference between OCN_T and OCN FILT. XMXL is the monthly varying maximum ocean mixed layer depth from the OCN_TC run. The variable $d h$ is the differential vertical length, and $d A$ is the differential horizontal area. The variable $-d$ is the chosen depth for vertical integration, and here we use $-d=$ $1000 \mathrm{~m}$. At each time step, the heat anomalies are integrated horizontally over the global ocean and vertically from XMXL to $1000 \mathrm{~m}$. By using XMXL, the OHU defined here represents the amount of heat that enters the permanent thermocline.

Figure 15 shows the time series of global OHU over the last 27 years of the simulation. We left out the first three years to avoid potential period for adjustment. $\mathrm{OHU}$ is calculated using monthly data and then smoothed with a 12-month running average. Results show that the modeled TCs can induce positive ocean heat uptake, and the magnitude of the annual average OHU is about $2.3 \times 10^{21} \mathrm{~J}$ in the upper $300 \mathrm{~m}$ and $5.3 \times$ $10^{21} \mathrm{~J}$ in the upper $1000 \mathrm{~m}$. The annual average TCinduced OHU can also be interpreted as an annual average heating rate, which corresponds to $0.17 \mathrm{PW}$ in the upper $1000 \mathrm{~m}$. The magnitude of annual OHU is comparable with previous estimates of $4.1 \times 10^{21} \mathrm{~J}$ in the upper 720-m depth in Bueti et al. (2014) and $4.4 \times 10^{21} \mathrm{~J}$ with a coarser TC wind forcing in Li and Sriver (2016). The maximum TC-induced annual ocean heat uptake in the upper $300 \mathrm{~m}$ in this study is $\sim 4.1 \times 10^{21} \mathrm{~J}$ (Fig. 15a). Levitus et al. (2000) estimated the interannual to decadal variability in upper 300-m ocean heat content over the late twentieth century to be on the order of $4 \times$ $10^{22} \mathrm{~J}$. Therefore, the TC-induced $\mathrm{OHU}$ is equivalent to about $10 \%$ of the total OHU variability.

We then analyze the depth dependence of the heat flux. The total heat flux across a chosen depth $z$ can be decomposed into several components (Wolfe et al. 2008):

$$
\overline{w H}=\bar{w} \bar{H}+\overline{w^{\prime} H^{\prime}}+\overline{w_{t} H_{t}}+\overline{w_{c} H_{c}},
$$

where $H=\rho C \theta$ is the specific heat content, $w$ is the vertical velocity, and the overbar indicates the time average. The right-hand side represents heat flux due to the mean circulation flow $\bar{w}$, eddies $w^{\prime}$, turbulent mixing $w_{t}$, and convection $w_{c}$. Because of the limited model output variables in the current study, we only focus on the first term and examine the distribution of TCinduced long-term mean globally integrated vertical heat flux due to the mean circulation $\bar{w} \bar{H}$.

Figure 16a shows the globally integrated vertical profile of heat flux in the upper $2000 \mathrm{~m}$ in CPL, OCN TC, and OCN_FILT. We find that all the model simulations show a downward heat flux throughout the ocean subsurface, and the magnitude and direction of the heat flux are consistent with results from other GCM studies (Wolfe et al. 2008; Cummins et al. 2016). The two oceanonly models simulate smaller downward heat transport than the CPL at 100-800 m, which may be mainly due to the differences in the vertical temperature distribution (see supplemental material). Figure 16b shows the differences between OCN_TC and OCN_FILT, revealing that TCs can enhance the mean downward heat flux in the upper $900 \mathrm{~m}$ through the mean flow. The maximum downward heat flux anomaly occurs at 100-m depth, with the maximum value of $\sim 0.06 \mathrm{PW}$.

In the POP2 ocean model used in this study, vertical diffusion is parameterized using the KPP vertical mixing scheme, which includes processes of shear instability, internal wave breaking, double diffusion, convection, and tidal mixing. Figure 16c shows TC-induced changes in the global average diabatic diffusivity of potential temperature from the sum of these processes. We found that TCs can enhance the global average diabatic thermal diffusivity at 40-250-m depth. The maximum increase is at 60 -m depth $\left(1 \times 10^{-3} \mathrm{~m}^{2} \mathrm{~s}^{-1}\right)$, which may be 

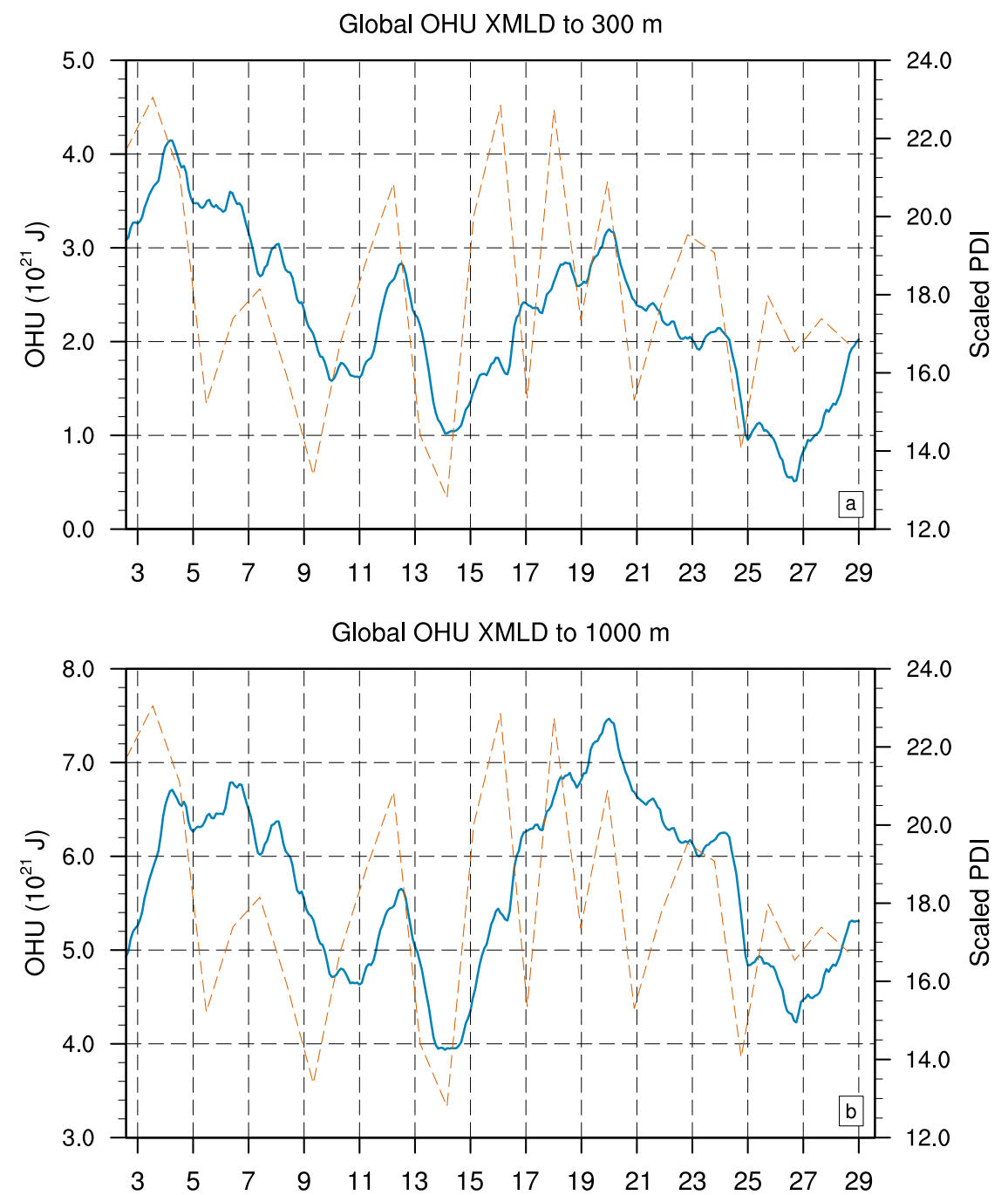

FIG. 15. Time series of annual TC-induced OHU (solid blue curves) and annual TC PDI (dashed orange curves). The ocean heat anomalies are integrated from the maximum mixed layer depth to (a) 300- and (b) $1000-\mathrm{m}$ depth. PDI is scaled by $1 \times 10^{-11}$.

mainly attributed to enhanced shear instability, as the depth corresponds to the depth of the boundary layer. Meanwhile, the negative total diffusivity anomaly above $35-\mathrm{m}$ depth is likely due to the deepening of the mixed layer.

To analyze the interannual variability of OHU and its relationship with the TC activity, we compare the time series of OHU to the time series of annually accumulated TC PDI (Fig. 15). In general, OHU covaries with PDI with an approximately 1-yr lag time: The annual average 300- and 1000-m OHU correlate with the PDI with a 1-yr lag maximum correlation coefficient of 0.5 and 0.42 , respectively. Moreover, since the response time of the ocean is slower, OHU does not have as strong year-to-year variability as PDI, and the time variations are smoother. For example, for the period of years 16-20, OHU continues to increase despite the quiet years (years 17 and 19) that occur between relatively active years (years 16,18, and 20), and reaches the highest by the end of year 20 . This suggests that multiyear TC variability can affect the OHU in an accumulative manner, and the interannual variability of TCs may have important implications for the variability of the ocean heat budget.

\section{Discussion and conclusions}

In this paper, we use a fully coupled high-resolution CESM simulation and a set of ocean model experiments to examine the impact of model-simulated TCs on the global ocean. Two ocean-only simulations are performed using boundary conditions with and without 

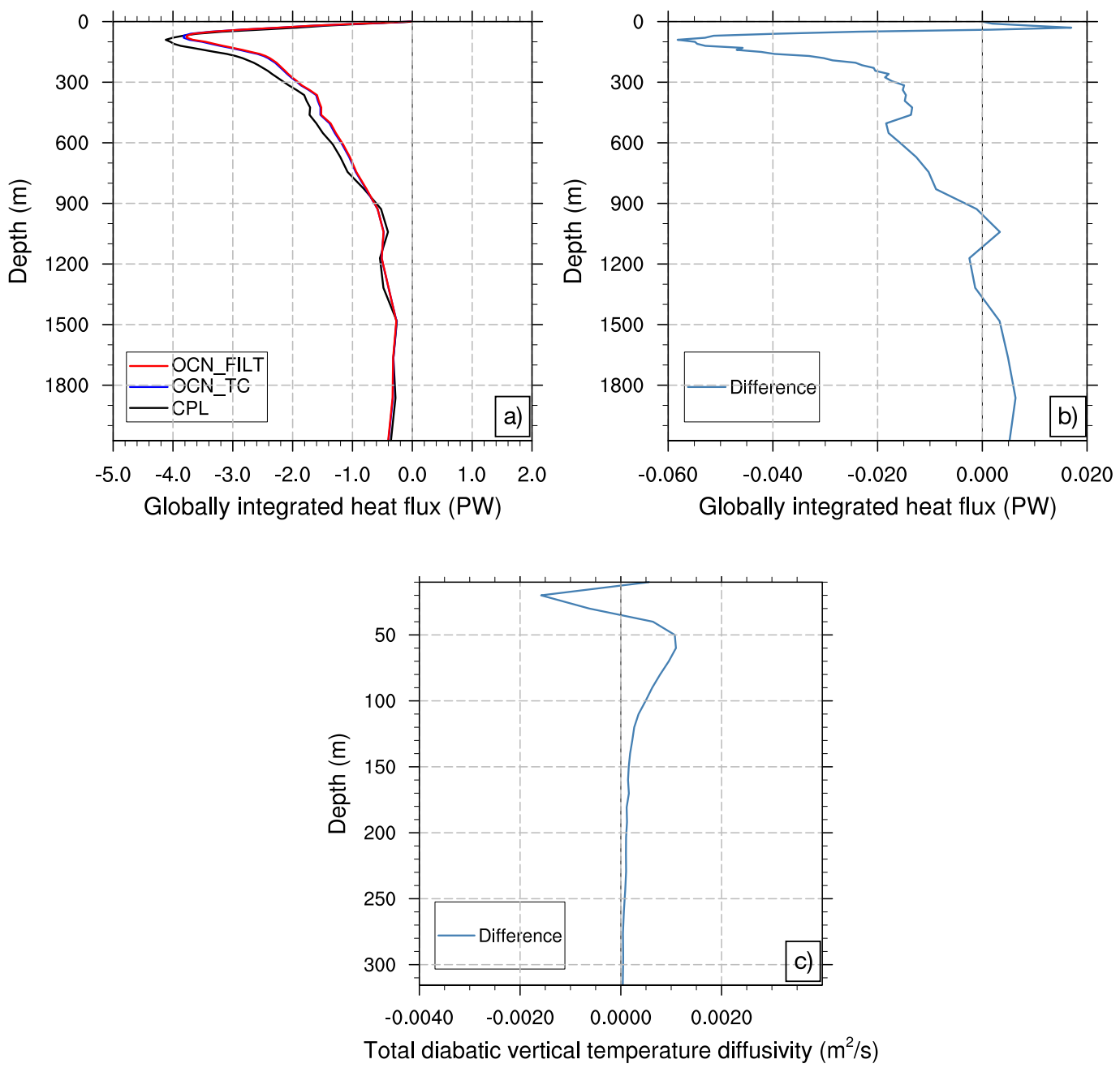

FIG. 16. (a) Long-term annual mean vertical heat flux (PW) due to mean circulation in the CPL (black), OCN_TC (blue), and OCN_FILT (red) simulations. (b) The differences of vertical heat flux between OCN_TC and OCN FILT. Negative values indicate downward heat flux. (c) Long-term mean TC-induced anomalous total diabatic vertical temperature diffusivity $\left(\mathrm{m}^{2} \mathrm{~s}^{-1}\right)$.

effects of TCs on the surface ocean. We aim to better understand how the high-resolution model's directly generated TCs can affect the modeled ocean state in order to provide insights into the physical understanding as well as model behavior regarding TCs' potential feedbacks to the large-scale climate within the "TC resolving" high-resolution Earth system models.

We find that the modeled TCs can induce changes in surface and subsurface ocean temperature patterns and seasonality. On annual average, we observe SST cooling (up to $0.5^{\circ} \mathrm{C}$ ) in major TC basins and SST warming $\left(\sim 0.1^{\circ} \mathrm{C}\right)$ at the higher latitudes. Changes in SST are generally consistent with previous ocean modeling studies using observation-based estimates of TC activity (e.g., Bueti et al. 2014; Vincent et al. 2013). The surface warming occurs in the winter season, which is due to the reemergence of subsurface heat anomalies associated with the seasonal variations of the mixed layer depth, as well as heat transport by the western boundary currents. This wintertime SST warming results in an anomalous SST gradient at the location critical for midlatitude winter storm track.

At the ocean subsurface across the equatorial Pacific, TC-induced heat anomalies propagate eastward along the main thermocline and accumulate in the equatorial eastern Pacific. In the meridional direction, the subsurface warm anomalies generally travel along the isotherms following the ocean overturning cells, with a tendency to converge back to the near-equator upwelling zone. In the northwestern Pacific, TCs can amplify the fast changes of late-winter midlatitude ocean mixed layer depth, resulting in a net column cooling around 
$30^{\circ}-35^{\circ} \mathrm{N}$, which then resides within the region of subtropical mode water, suggesting potential influence on the subtropical mode water formation.

The modeled TCs can deepen the annual average ocean mixed layer in the major TC basins and at higher latitudes. In particular, the largest changes occur in the upstream Kuroshio Extension region, where TCs can amplify the rapid seasonal changes of the background mixed layer depth. Moreover, we find that TCs can strengthen ocean gyre circulations and meridional overturning circulations (MOCs), though the changes are small. The maximum overturning in the subtropical cell is enhanced by $3 \%$ on global average and $1 \%$ in the Atlantic.

In addition, we find that the modeled TCs can influence ocean MHT. In general, TCs amplify the background MHT patterns, featuring enhanced poleward heat transport and cross-equator northward transport. However, the contribution of TC-induced anomalies to the background total MHT is not significant, accounting for $\sim 2.5 \%$ of the background peak transport. Anomalous heat converges at the equatorial region around $2^{\circ}-$ $12^{\circ} \mathrm{S}$ and in the higher latitudes, corresponding to the anomalous heat transport by the overturning cells and the western boundary currents. We find that the influence of the enhanced poleward transport overcomes the equatorial convergence in the northern equatorial region, which may be due to the latitudinal distribution of TC-induced diffusivity in the model.

This analysis shows that TCs can induce positive ocean heat uptake in the model, and TC-induced OHU covaries with the annual total TC PDI on interannual time scales with a lag time of approximately one year. Moreover, multiyear TC activity can influence OHU accumulatively, suggesting important implications for interannual climate variability.

The current study contains several important caveats. First, as is mentioned in the experimental design, the regridding of the atmosphere boundary conditions may induce inconsistencies in surface fluxes during the initialization of the ocean simulation, and the ocean model is not in perfect equilibrium. For this reason, though OCN_TC is intended to mimic the response in CPL, the mean ocean states are not exactly the same between the two simulations. For example, compared to CPL, OCN $\mathrm{TC}$ is cooler in the upper $150 \mathrm{~m}\left(\sim 0.2^{\circ}-0.5^{\circ} \mathrm{C}\right)$ in the tropical and subtropical ocean and slightly warmer below 200-m depth in the mid- to high latitudes (Figs. S1S3). The influence introduced by this initial condition issue is assumed to be the same for OCN_TC and OCN FILT, and these effects are minimized by focusing on anomalies between the two simulations. We find no apparent trend in TC-induced anomalous SST, ocean potential temperature in the upper $1000 \mathrm{~m}$ (Figs. S5, S6), and ocean heat uptake (Fig. 15), which supports this assumption. However, when asking how TCs can influence the simulated ocean in the coupled atmosphereocean system, the difference of ocean state in OCN_TC and CPL should be considered. Compared to CPL, the relatively lower potential temperature at around $100-\mathrm{m}$ depth in OCN_TC indicates increased upper-ocean stability in the tropical ocean, which may act to restrain TC-induced vertical mixing in the boundary layer.

A second caveat is related to ocean horizontal grid resolution. The combination of a $0.25^{\circ}$ atmosphere and a $1^{\circ}$ ocean may underestimate the TC wind forcing into the ocean. This is a major factor influencing the estimated impact of TCs in this study. In fact, Rimac et al. (2013) and Li and Sriver (2016) found that the coarseresolution ocean grid tends to underestimate TC surface wind stress, which will result in underestimated momentum input and vertical mixing in the ocean. In addition, ocean grid resolution largely affects the representation of small-scale oceanic features that are important for TC-ocean interactions. In particular, representation of mesoscale ocean eddies is important for simulating TC-induced vertical mixing and meridional heat transport. The nominal $1^{\circ}$ POP ocean model has varying horizontal grids that are finest $\left(0.27^{\circ}\right)$ near the equator and grow coarser poleward. Mesoscale ocean eddies are partially permitted within $20^{\circ} \mathrm{S}-20^{\circ} \mathrm{N}$ and largely parameterized elsewhere. The underrepresented eddies in the model may influence the simulated TCs' impact on MHT. Moreover, ocean grid resolution can also affect the representation of nearinertial waves (Cuypers et al. 2013), which are critical for simulating the strength of near-inertial wind power input and the subsequent entrainment. A recent study ( $\mathrm{Su}$ et al. 2018) found that ocean submesoscale processes play a key role in vertical heat transport and mixed layer depth, the representation of which can also influence the simulation results. Therefore, a higher-resolution ocean model is desirable for better understanding the physical nature of TCs' impact on the ocean. Here we focus on examining the impact of these resolved TCs on the simulated large-scale climate mean state in these commonly used model configurations. Modeling studies with a high-resolution ocean component will be performed in the future.

In addition, 30 years may not be long enough to capture the changes of the meridional overturning strength and meridional ocean heat transport. The current simulations are limited by the high computational cost of the high-resolution Earth system modeling. A higherresolution experiment with longer integration time is desirable in future studies. 
Moreover, the current study uses the ocean-only configuration. Results such as SST cooling, changes of SST gradient, and meridional ocean heat transport may be different when including active air-sea coupling. The lack of atmosphere coupling may also induce overestimated ocean heat loss in OCN_FILT, as the warmer SST in OCN_FILT and the nonresponding atmosphere boundary can result in a flux imbalance. In addition, the impact of TCs on the ocean may be model dependent. The result can be tightly related to the simulated TC characteristics, ocean mixing scheme, simulated ocean stratification, and ocean grid resolution.

Acknowledgments. This research is part of the Blue Waters sustained-petascale computing project, which is supported by the National Science Foundation (Awards OCI-0725070 and ACI-1238993) and the state of Illinois. Blue Waters is a joint effort of the University of Illinois at Urbana-Champaign and its National Center for Supercomputing Applications (NCSA). This work is funded by the NCSA fellowship program. High-resolution daily and 6-hourly data output are archived at the University of Illinois and are available from the authors upon request. We acknowledge Kerry Emanuel for providing best track data (http://eaps4.mit.edu/faculty/ Emanuel/products).

\section{REFERENCES}

Bacmeister, J. T., K. A. Reed, C. Hannay, P. Lawrence, S. Bates, J. E. Truesdale, N. Rosenbloom, and M. Levy, 2018: Projected changes in tropical cyclone activity under future warming scenarios using a high-resolution climate model. Climatic Change, 146, 547-560, https://doi.org/10.1007/s10584-016-1750-x.

Boos, W. R., J. R. Scott, and K. A. Emanuel, 2004: Transient diapycnal mixing and the meridional overturning circulation. J. Phys. Oceanogr., 34, 334-341, https://doi.org/10.1175/ 1520-0485(2004)034<0334:TDMATM >2.0.CO;2.

Bueti, M. R., I. Ginis, L. M. Rothstein, and S. M. Griffies, 2014: Tropical cyclone-induced thermocline warming and its regional and global impacts. J. Climate, 27, 6978-6999, https:// doi.org/10.1175/JCLI-D-14-00152.1.

Cheng, L., J. Zhu, and R. L. Sriver, 2015: Global representation of tropical cyclone-induced short-term ocean thermal changes using Argo data. Ocean Sci., 11, 719-741, https://doi.org/10.5194/ os-11-719-2015.

Craig, A. P., M. Vertenstein, and R. Jacob, 2011: A new flexible coupler for Earth system modeling developed for CCSM4 and CESM1. Int. J. High Perform. Comput. Appl., 26, 31-42, https://doi.org/10.1177/1094342011428141.

Cummins, P. F., D. Masson, and O. A. Saenko, 2016: Vertical heat flux in the ocean: Estimates from observations and from a coupled general circulation model. J. Geophys. Res. Oceans, 121, 3790-3802, https://doi.org/10.1002/2016JC011647.

Cuypers, Y., X. Le Vaillant, P. Bouruet-Aubertot, J. Vialard, and M. J. McPhaden, 2013: Tropical storm-induced near-inertial internal waves during the Cirene experiment: Energy fluxes and impact on vertical mixing. J. Geophys. Res. Oceans, 118, 358-380, https://doi.org/10.1029/2012JC007881.

Danabasoglu, G., W. G. Large, J. J. Tribbia, P. R. Gent, B. P. Briegleb, and J. C. McWilliams, 2006: Diurnal coupling in the tropical oceans of CCSM3. J. Climate, 19, 2347-2365, https:// doi.org/10.1175/JCLI3739.1.

Dare, R. A., and J. L. McBride, 2011: Sea surface temperature response to tropical cyclones. Mon. Wea. Rev., 139, 3798-3808, https://doi.org/10.1175/MWR-D-10-05019.1.

Davis, C. A., 2018: Resolving tropical cyclone intensity in models. Geophys. Res. Lett., 45, 2082-2087, https://doi.org/10.1002/ 2017 GL076966.

Duchon, C. E., 1979: Lanczos filtering in one and two dimensions. J. Appl. Meteor., 18, 1016-1022, https://doi.org/10.1175/ 1520-0450(1979)018<1016:LFIOAT >2.0.CO;2.

Emanuel, K., 2001: Contribution of tropical cyclones to meridional heat transport by the oceans. J. Geophys. Res., 106, 1477114 781, https://doi.org/10.1029/2000JD900641.

_ 2005: Increasing destructiveness of tropical cyclones over the past 30 years. Nature, 436, 686-688, https://doi.org/10.1038/ nature 03906.

Fedorov, A. V., C. M. Brierley, and K. Emanuel, 2010: Tropical cyclones and permanent El Niño in the early Pliocene epoch. Nature, 463, 1066-1070, https://doi.org/10.1038/nature08831.

Ganachaud, A., and C. Wunsch, 2000: Improved estimates of global ocean circulation, heat transport and mixing from hydrographic data. Nature, 408, 453-457, https://doi.org/10.1038/35044048; Corrigendum, 410, 240, https://doi.org/10.1038/35065660.

Gent, P. R., and J. C. McWilliams, 1990: Isopycnal mixing in ocean circulation models. J. Phys. Oceanogr., 20, 150-155, https://doi.org/ 10.1175/1520-0485(1990)020<0150:IMIOCM > 2.0.CO;2.

Ginis, I., 2002: Tropical cyclone-ocean interactions. AtmosphereOcean Interactions, W. Perrie, Ed., Advances in Fluid Mechanics, Vol. 1, WIT Press, 83-114.

Graff, L. S., and J. H. LaCasce, 2012: Changes in the extratropical storm tracks in response to changes in SST in an AGCM. $J$. Climate, 25, 1854-1870, https://doi.org/10.1175/JCLI-D-11-00174.1.

Hanawa, K., and L. D. Talley, 2001: Mode waters. Ocean Circulation and Climate, G. Siedler, J. Church, and J. Gould, Eds., International Geophysics Series, Vol. 77, Academic Press, 373-386, https://doi.org/10.1016/S0074-6142(01)80129-7.

Hu, A., and G. A. Meehl, 2009: Effect of the Atlantic hurricanes on the oceanic meridional overturning circulation and heat transport. Geophys. Res. Lett., 36, L03702, https://doi.org/10.1029/ 2008GL036680.

Hurrell, J. W., and Coauthors, 2013: The Community Earth System Model: A framework for collaborative research. Bull. Amer. Meteor. Soc., 94, 1339-1360, https://doi.org/10.1175/ BAMS-D-12-00121.1.

Jaimes, B., and L. K. Shay, 2009: Mixed layer cooling in mesoscale oceanic eddies during Hurricanes Katrina and Rita. Mon. Wea. Rev., 137, 4188-4207, https://doi.org/10.1175/2009MWR2849.1.

Jansen, M., and R. Ferrari, 2009: Impact of the latitudinal distribution of tropical cyclones on ocean heat transport. Geophys. Res. Lett., 36, L06604, https://doi.org/10.1029/2008GL036796.

,-- , and T. A. Mooring, 2010: Seasonal versus permanent thermocline warming by tropical cyclones. Geophys. Res. Lett., 37, L03602, https://doi.org/10.1029/2009GL041808.

Jullien, S., and Coauthors, 2012: Impact of tropical cyclones on the heat budget of the South Pacific Ocean. J. Phys. Oceanogr., 42, 1882-1906, https://doi.org/10.1175/JPO-D-11-0133.1.

Korty, R. L., K. A. Emanuel, and J. R. Scott, 2008: Tropical cyclone-induced upper-ocean mixing and climate: Application 
to equable climates. J. Climate, 21, 638-654, https://doi.org/ 10.1175/2007JCLI1659.1.

Large, W. G., and S. G. Yeager, 2004: Diurnal to decadal global forcing for ocean and sea-ice models: The data sets and flux climatologies. NCAR Tech. Note NCAR/TN-460+STR, 105 pp., https://doi.org/10.5065/D6KK98Q6.

— J. J. McWilliams, and S. C. Doney, 1994: Oceanic vertical mixing: A review and a model with a nonlocal boundary layer parameterization. Rev. Geophys., 32, 363-403, https://doi.org/ 10.1029/94RG01872.

, G. Danabasoglu, S. C. Doney, and J. C. McWilliams, 1997: Sensitivity to surface forcing and boundary layer mixing in a global ocean model: Annual-mean climatology. J. Phys. Oceanogr., 27, 2418-2447, https://doi.org/10.1175/1520-0485(1997)027<2418: $\mathrm{STSFAB}>2.0 . \mathrm{CO} ; 2$

Lawrence, D. M., K. W. Oleson, M. G. Flanner, C. G. Fletcher, P. J. Lawrence, S. Levis, S. C. Swenson, and G. B. Bonan, 2012: The CCSM4 land simulation, 1850-2005: Assessment of surface climate and new capabilities. J. Climate, 25, 2240-2260, https:// doi.org/10.1175/JCLI-D-11-00103.1.

Levitus, S., J. I. Antonov, T. P. Boyer, and C. Stephens, 2000: Warming of the World Ocean. Science, 287, 2225-2229, https:// doi.org/10.1126/science.287.5461.2225.

Li, H., and R. L. Sriver, 2016: Effects of ocean grid resolution on tropical cyclone-induced upper ocean responses using a global ocean general circulation model. J. Geophys. Res. Oceans, 121, 8305-8319, https://doi.org/10.1002/2016JC011951.

—, and — , 2018: Tropical cyclone activity in the highresolution Community Earth System Model and the impact of ocean coupling. J. Adv. Model. Earth Syst., 10, 165-186, https://doi.org/10.1002/2017MS001199.

,-- , and M. Goes, 2016: Modeled sensitivity of the Northwestern Pacific upper-ocean response to tropical cyclones in a fully coupled climate model with varying ocean grid resolution. J. Geophys. Res. Oceans, 121, 586-601, https://doi.org/ 10.1002/2015JC011226.

Maltrud, M. E., and J. L. McClean, 2005: An eddy resolving global 1/10 ${ }^{\circ}$ ocean simulation. Ocean Modell., 8, 31-54, https://doi.org/ 10.1016/j.ocemod.2003.12.001.

Mei, W., F. Primeau, J. C. McWilliams, and C. Pasquero, 2013: Sea surface height evidence for long-term warming effects of tropical cyclones on the ocean. Proc. Natl. Acad. Sci. USA, 38, 15 207-15 210, https://doi.org/10.1073/pnas.1306753110.

Moon, I.-J., I. Ginis, T. Hara, and B. Thomas, 2007: A physicsbased parameterization of air-sea momentum flux at high wind speeds and its impact on hurricane intensity predictions. Mon. Wea. Rev., 135, 2869-2878, https://doi.org/10.1175/MWR3432.1.

Neale, R. B., J. Richter, S. Park, P. H. Lauritzen, S. J. Vavrus, P. J. Rasch, and M. Zhang, 2013: The mean climate of the Community Atmosphere Model (CAM4) in forced SST and fully coupled experiments. J. Climate, 26, 5150-5168, https://doi.org/ 10.1175/JCLI-D-12-00236.1.

Powell, M. D., P. J. Vickery, and T. A. Reinhold, 2003: Reduced drag coefficient for high wind speeds in tropical cyclones. Nature, 422, 279-283, https://doi.org/10.1038/nature01481.

Price, J. F., 1981: Upper ocean response to a hurricane. J. Phys. Oceanogr., 11, 153-175, https://doi.org/10.1175/1520-0485 (1981)011<0153:UORTAH >2.0.CO;2.

Rimac, A., J.-S. von Storch, C. Eden, and H. Haak, 2013: The influence of high-resolution wind stress field on the power input to near-inertial motions in the ocean. Geophys. Res. Lett., $\mathbf{4 0}$, 4882-4886, https://doi.org/10.1002/grl.50929.
Scoccimarro, E., and Coauthors, 2011: Effects of tropical cyclones on ocean heat transport in a high-resolution coupled general circulation model. J. Climate, 24, 4368-4384, https://doi.org/ 10.1175/2011JCLI4104.1.

_ , P. G. Fogli, K. A. Reed, S. Gualdi, S. Masina, and A. Navarra, 2017: Tropical cyclone interaction with the ocean: The role of high-frequency (subdaily) coupled processes. J. Climate, 30, 145-162, https://doi.org/10.1175/JCLI-D-16-0292.1.

Small, R. J., and Coauthors, 2014: A new synoptic scale resolving global climate simulation using the Community Earth System Model. J. Adv. Model. Earth Syst., 6, 1065-1094, https://oi.org/ 10.1002/2014MS000363.

Smith, R., and Coauthors, 2010: The Parallel Ocean Program (POP) reference manual: Ocean component of the Community Climate System Model (CCSM) and Community Earth System Model (CESM). Los Alamos National Laboratory Tech. Rep. LAUR-10-01853, 141 pp., http://www.cesm.ucar.edu/ models/cesm1.0/pop2/doc/sci/POPRefManual.pdf.

Sriver, R. L., and M. Huber, 2007: Observational evidence for an ocean heat pump induced by tropical cyclones. Nature, 447, 577-580, https://doi.org/10.1038/nature05785.

- , and -2010 : Modeled sensitivity of upper thermocline properties to tropical cyclone winds and possible feedbacks on the Hadley circulation. Geophys. Res. Lett., 37, L08704, https:// doi.org/10.1029/2010GL042836.

Su, Z., J. Wang, P. Klein, A. F. Thompson, and D. Menemenlis, 2018: Ocean submesoscales as a key component of the global heat budget. Nat. Commun., 9, 775, https://doi.org/10.1038/ s41467-018-02983-w.

Trenberth, K. E., and J. M. Caron, 2001: Estimates of meridional atmosphere and ocean heat transports. J. Climate, $\mathbf{1 4}$ 3433-3443, https://doi.org/10.1175/1520-0442(2001)014<3433: EOMAAO $>2.0 . \mathrm{CO} ; 2$.

Vincent, E. M., G. Madec, M. Lengaigne, J. Vialard, and A. Koch-Larrouy, 2013: Influence of tropical cyclones on sea surface temperature seasonal cycle and ocean heat transport. Climate Dyn., 41, 2019-2038, https://doi.org/10.1007/s00382012-1556-0.

Wang, J.-W., W. Han, and R. L. Sriver, 2012a: Impact of tropical cyclones on the ocean heat budget in the Bay of Bengal during 1999: 1. Model configuration and evaluation. J. Geophys. Res., 117, C09020, https://doi.org/10.1029/2012JC008372.

,-- , and $-2012 \mathrm{~b}$ : Impact of tropical cyclones on the ocean heat budget in the Bay of Bengal during 1999: 2. Processes and interpretations. J. Geophys. Res., 117, C09021, https://doi.org/10.1029/2012JC008373.

Wehner, M. F., and Coauthors, 2014: The effect of horizontal resolution on simulation quality in the Community Atmospheric Model, CAM5.1. J. Adv. Model. Earth Syst., 6, 980997, https://doi.org/10.1002/2013MS000276.

Williams, R. G., 1989: The influence of air-sea interaction on the ventilated thermocline. J. Phys. Oceanogr., 19, 1255-1267, https:// doi.org/10.1175/1520-0485(1989)019<1255:TIOAIO>2.0.CO;2.

Wolfe, C. L., P. Cessi, J. L. McClean, and M. E. Maltrud, 2008: Vertical heat transport in eddying ocean models. Geophys. Res. Lett., 35, L23605, https://doi.org/10.1029/2008GL036138.

Zedler, S. E., T. D. Dickey, S. C. Doney, J. F. Price, X. Yu, and G. L. Mellor, 2002: Analyses and simulations of the upper ocean's response to Hurricane Felix at the Bermuda Testbed Mooring site: 13-23 August 1995. J. Geophys. Res., 107, 3232, https://doi.org/10.1029/2001JC000969. 